\title{
Restoring Force Model of an Energy-Dissipation Joint in Hybrid Frames: Simplified Skeleton Curve and Hysteretic Rules
}

\author{
Yanhua Wang $\mathbb{D}^{1},{ }^{1}$ Yan Feng, ${ }^{1}$ Dongsheng Huang, ${ }^{2}$ Zirui Huang, ${ }^{1}$ and Zhongfan Chen ${ }^{1}$ \\ ${ }^{1}$ Key Laboratory of RC \& PC Structures of Ministry of Education, Southeast University, Nanjing 210096, China \\ ${ }^{2}$ National Engineering Research Center of Biomaterials, Nanjing Forestry University, Nanjing 210037, China \\ Correspondence should be addressed to Yanhua Wang; wyh00737@seu.edu.cn
}

Received 29 September 2019; Accepted 24 April 2020; Published 28 May 2020

Academic Editor: Giuseppe Quaranta

Copyright (C) 2020 Yanhua Wang et al. This is an open access article distributed under the Creative Commons Attribution License, which permits unrestricted use, distribution, and reproduction in any medium, provided the original work is properly cited.

In this paper, a restoring force model, composed of a trilinear skeleton curve and hysteretic rules, is proposed based on nine pseudostatic tests of the energy-dissipation joint under horizontal low cyclic loading. The critical points of the simplified skeleton curve are obtained via theoretical derivation and FE simulation. The hysteretic rules for the joints are simplified as a concave hexagon, where the parameters of the critical points are optimized by the genetic algorithm (GA). Using the established trilinear skeleton curve, three different working stages, i.e., elastic, hardening, and softening, were divided by the critical points and the moment stiffness of three stages can be calculated. The proposed hysteretic rules of each stage can reveal and explain the "pinching" in the cyclic loading, which make it easier to understand the mechanism of the energy-dissipation joint. The comparison between the restoring force model and the tests shows that the simplified skeleton curves, the established hysteretic rules, and the ductility and the damping ratio are consistent with the experimental results. Finally, the effectiveness of the established restoring force model is verified.

\section{Introduction}

In the past few decades, engineered bamboo products (EBPs) have emerged as alternatives to traditional building materials because of their advantages, such as energy saving and environmental friendliness $[1,2]$. As the manufacturing technology is getting increasingly mature, the promotion of application of wood and bamboo materials in mid- and high-rise buildings has caught great attention of researchers worldwide [3-8].

However, compared with concrete and steel, there are some inherent limitations of EBPs when used as perpendicular bearing components, i.e., the accumulated creep and requirement for a larger size. To overcome the issues mentioned above, a hybrid frame made up of steel columns and engineered bamboo beams is proposed as an effective solution $[9,10]$. Obviously, the connection between the steel column and engineered bamboo beam becomes an essential aspect of steel-engineered bamboo frame.
Studies on variable parameters have been conducted to explore the appropriate design methods of the joint as a reliable connection. The dowel and bolt are the most commonly used joints in modern wood or EBP buildings, whose ductility is achieved by means of the plastic deformation in metallic connectors [11-15]. Conversely, in heavy portal frames, the energy-dissipation capacity of the connections turns out to be relatively low because of the limited number of joints. To improve the hysteretic performance of timber or EBP connections, some new joints or reinforcement methods were proposed. An innovative posttensioned beam-column timber joint, which turned out to be of good structural performances, has been developed and studied by many researchers [16, 17]. Other reinforcement methods such as gluing wood-based panels on each side of the shear planes, by orienting unidirectional fibers perpendicular to the grain and inserting a box-type steel bracket between timber beam and column [10, 18-27], were tested, and satisfactory results were obtained. 
Among these studies, Huang et al. [28] proposed a semirigid joint made up of a steel hinge and a pair of top and seat brackets to carry the shear force and moment from the end of the beam, as shown in Figure 1. In this setup, the joint can serve as a frame connection and an energy-dissipation device. Low cyclic loading experiments for nine joints were conducted in Nanjing Forest University, and the results revealed that the joint provided sufficient strength and stiffness to satisfy the requirements of serviceability, demonstrating a satisfactory energy-dissipation capacity. With a proper design, the ductility ratio and damping ratio of the connections can reach more than 3.0 and 30\%, respectively. Huang et al. [28] also suggested a formula to predict the load-carrying capacity of the proposed semirigid joint together with a design method to fully display its load-carrying capacity and ductility. The research results and theoretical derivation verified the pronounced advantages of the joint in connecting the steel-engineered bamboo hybrid frame, which requires further study to investigate its restoring characteristics.

The cyclic restoring force model is an useful tool for performing seismic analysis of energy-dissipation joints in mid- and high-rise buildings [29, 30]. Based on the hysteresis loops and skeleton curves of energy-dissipation joints, a simplified trilinear skeleton curve is constructed, where the characteristic values can be obtained via the load-carrying capacity formula and theoretic derivation. The hysteretic rules of a single loop have a reversed S-shape, which can be modeled by a concave hexagon. In this paper, the characteristic values of the concave hexagon are optimized by the genetic algorithm.

\section{Brief Introduction of the Test}

The schematic picture of the energy-dissipation joint is illustrated in Figure 1. The base panel and the stub were connected through a $20 \mathrm{~mm}$ dimeter bolt. The PSB panels were mounted on the two sides of steel stub of the connection, respectively, through 12 bolts of $22 \mathrm{~mm}$ in dimeter. The middle parts of the two energy-dissipation plates (EDPs in the following) were welded on the stub symmetrically, while one end was weld on the base panel.

The details of the test connections (i.e., the diameter and spacing of the bolts, the sizes of the base panel, and stub) were designed with a suitable over strength. In this way, the bolt connection is stronger than the EDPs and the tension and compression forces lead to the yielding or buckling of the EDPs that dissipated energy when exerted earthquake or reversed loading. Theoretically, the dimension of the brackets is one of the major factors impacting on the mechanical behavior of the connection.

According to the purpose of the energy-dissipation joint design [28], the width-to-thickness ratio of the energydissipation plate should be greater than $1 / 5$ to ensure that there is only minimal shear under seismic loading. Presimulations in ABAQUS with variable widths, thicknesses, and cross sections were carried out to study the effect of the buckling stress of the plate, which showed that the length-tothickness ratio was a major and reliable factor to explore the hysteretic behaviors of energy-dissipation plate (see Section 4.1.2). Therefore, a group of tests were performed to explore the effect of the length-to-thickness ratio on the momentcarrying capacity of the energy-dissipation joint by changing thicknesses with identical cross section and length. The parameters of the tests are presented in Table 1, where $l$ is the length of EDP, $b$ is the width of EDP, and $t$ is the thickness of EDP.

All specimens were loaded under a lateral cyclic force without axial pressure. For the convenience of loading, the specimens were rotated 90 degrees compared to their actual service position in the steel-engineered bamboo frame [28]. Using the setup presented in Figure 2(b), the engineered bamboo beam could be idealized as a cantilever beam that is fixed at the steel column and free at the other end. The lengths of the beam and column were $2 \mathrm{~m}$ and $1.2 \mathrm{~m}$ to avoid significant influence on the connection [31]. Hence, a similar bending moment to that in an actual steel-engineered bamboo hybrid frame was exerted on the specimens. The advantages of the setup also include the convenience for calculation and installment.

Preloading was conducted to check if all the bolt-joints were properly mounted and worked well and then unloading the actuator to zero to reset the acquisition system. Load was controlled by the movement of actuator at the speed of $4 \mathrm{~mm} / \mathrm{min}$ before the EDP yielding and of $0.2 \Delta \mathrm{mm} / \mathrm{min}$ after the first yielding of the EDP, where $\Delta$ represents the top displacement of first yielding in the EDP. Three cycles were carried out for each loading grade after the first yielding occurred [32, 33]. The loading-unloading regime is illustrated in Figure 2(c).

\section{Analysis of the Experimental Results}

According to the nine experimental results, the failure modes can be categorized into two different types, as presented in Table 2.

Since the joint is designed to dissipate earthquake energy by the EDPs, the fatigue strength of the weld in failure mode II dominates the load-carrying capacity of the joint and the EDPs are too thick to fully display their energy-dissipation ability. According to design suggestions in [28], the lengthto-thickness ratio should be limited in the range of 9 to 16 . Only the first 4 tests in Table 1 meet the requirement. Besides that, there are only two working stages in the skeleton curves of the last 5 tests, due to the experimental setups' limits. Since the analytical model is intended to reveal the whole working stages, only the results of the first four groups in Table 1 were used for evaluating these coefficients.

As summarized from the hysteresis loops and skeleton curves in [28], a typical skeleton curve can be divided into three stages, as presented in Figure 3. The characteristics of the three working stages are included in Table 3.

The initial stiffness and moment-carrying capacity of the joint were also presented by Huang et al. [28] so that the stiffness in the elastic stage (I) and the maximum moment of the joint can be calculated. However, when structures undergo strong lateral forces (i.e., earthquakes and wind), the energy is dissipated by joints when the elastic stage is 


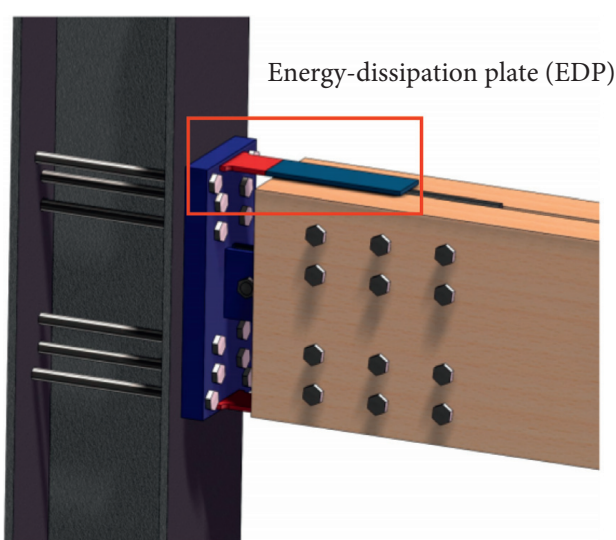

(a)

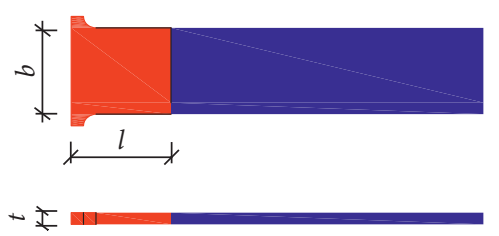

(b)

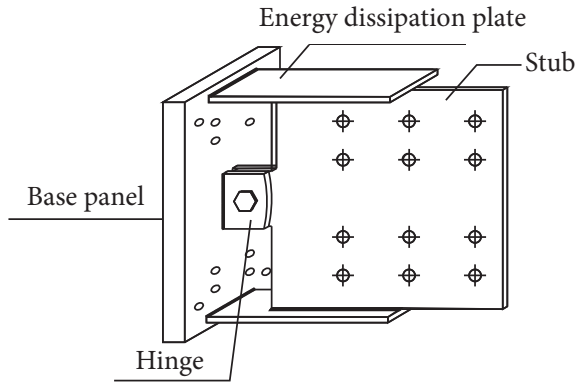

(c)

FIGURE 1: Energy-dissipation joint for hybrid frames: (a) schematic picture; (b) details of EDP; (c) details of the connection.

TABLE 1: Parameters of the tests.

\begin{tabular}{lcccc}
\hline Specimen & Length of EDP $(\mathrm{mm})$ & Width of EDP $(\mathrm{mm})$ & Thickness of EDP $(\mathrm{mm})$ & Length-to-thickness ratio \\
\hline$J-6-1$ & 80 & 100 & 6 & 13.3 \\
$J-8-1, J-8-2, J-8-3$ & 80 & 75 & 8 & 10 \\
$J-10-1, J-10-2, J-10-3$ & 80 & 60 & 10 & 8 \\
$J-12-1, J-12-2$ & 80 & 50 & 12 & 6.67 \\
\hline
\end{tabular}

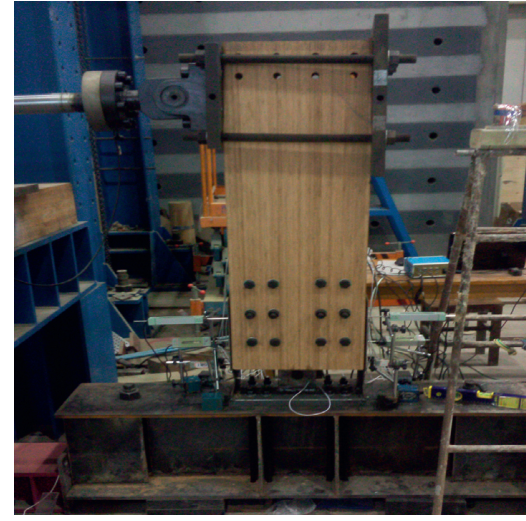

(a)

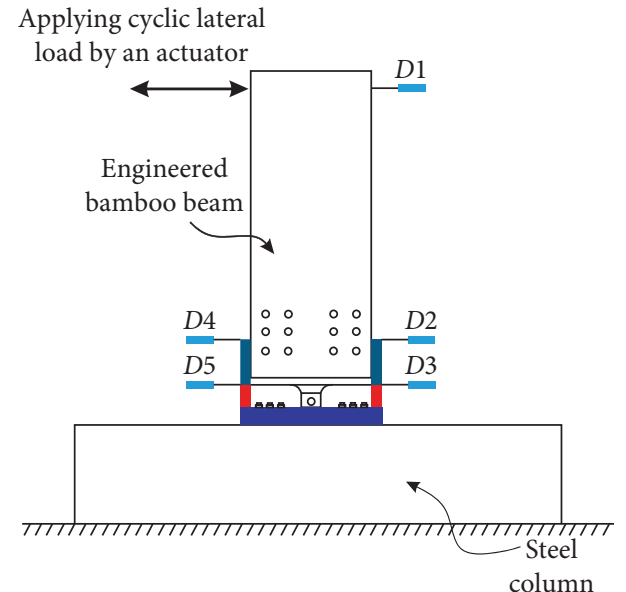

(b)

FIgURe 2: Continued. 


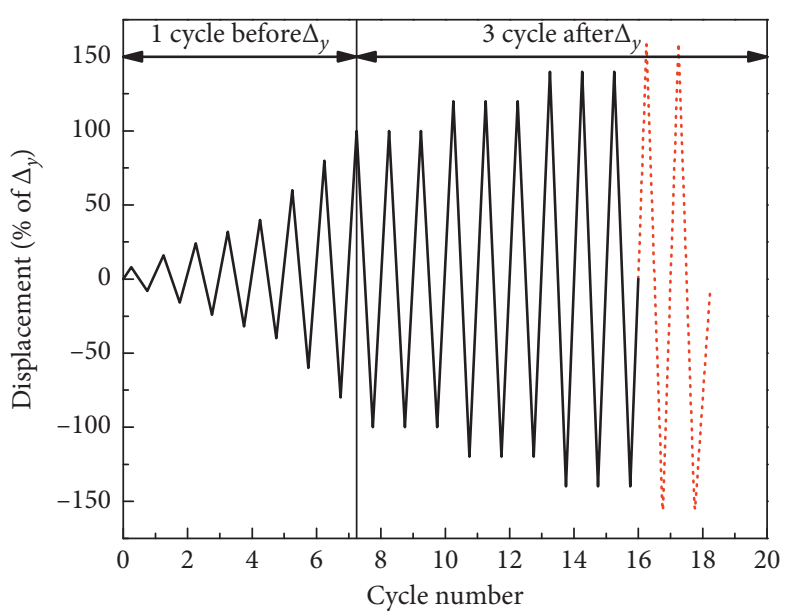

(c)

FIGURE 2: The energy-dissipation joint tests: details of the experimental specimen (a); schematic picture (b); loading regime of the test (c).

TABLE 2: The experimental results of the energy-dissipation joint.

\begin{tabular}{|c|c|c|c|c|}
\hline Specimen & Thickness of EDP $(\mathrm{mm})$ & Failure mode & Failure position & Failure characteristics [28] \\
\hline$J-6-1$ & 6 & & & \\
\hline$J-8-1, J-8-2, J-8-3$ & 8 & I & The middle of the EDP after buckling & \\
\hline$J-10-1, J-10-2, J-10-3$ & 10 & & & \\
\hline$J-12-1, J-12-2$ & 12 & II & The weld of the EDP-to-base panel & \\
\hline
\end{tabular}

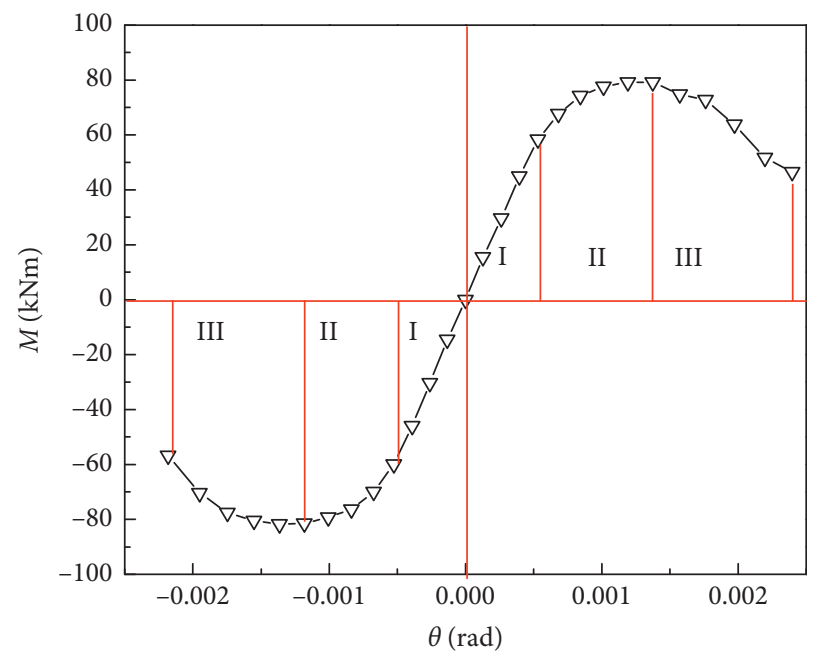

FIgURE 3: A typical skeleton curve of the energy-dissipation joint test. 
TABLE 3: Three working stages of a typical skeleton curve.

\begin{tabular}{|c|c|c|c|}
\hline $\begin{array}{l}\text { Working } \\
\text { stages }\end{array}$ & $M-\theta$ relationship & $\begin{array}{l}\text { Working status of } \\
\text { EDP }\end{array}$ & Working characteristics [28] \\
\hline $\mathrm{I}$ & Linear & Elastic & No damage of each components \\
\hline II & Nonlinear curve & Buckling & $\begin{array}{c}\text { By increasing the displacement or load, the strain exceeds its elastic limit, and } \\
\text { the EDP of the joint begins to buckle }\end{array}$ \\
\hline III & $\begin{array}{l}\text { A segment with negative } \\
\text { stiffness }\end{array}$ & Failure & $\begin{array}{c}\text { At the end of stage (II), the higher the displacement, the lower the load until } \\
\text { the failure of the joint occurs }\end{array}$ \\
\hline
\end{tabular}

exceeded. Therefore, the restoring force model including the nonlinear behavior of the joint should be studied.

The restoring force characteristics can be represented by a simplified skeleton curve and the hysteretic rules. The method to construct the restoring force model based on the experimental results (i.e., the skeleton curve and hysteresis loops) is explained as following: (1) by simplifying the nonlinear segments (hardening and softening segments) into straight lines with constant slope, the experimental skeleton curve can be transferred as a trilinear curve with six critical points; (2) the hysteretic rules can be simplified as a hexagon concluded from every single loop, where the maximum points can be obtained from the simplified skeleton curve and the other critical points need to be determined with GA.

Using the established trilinear skeleton curve, three different working stages, namely, elastic, hardening, and softening, were identified and defined by the critical points and the moment stiffness relationship of the three stages. The proposed hysteretic rules of each stages reveal and explain the "pinching" in the cyclic loading, which make it easier to understand the mechanism of the energy-dissipation joint.

\section{Restoring Force Model of the Energy- Dissipation Joint}

Based on the analysis of the nine pseudostatic tests of the energy-dissipation joint and the extended FE simulation, the critical points of the energy-dissipation joint with different sizes can be calculated. The restoring force model of this type joint is constructed, where the model parameters obtained can work for other connections of the same type.

4.1. Simplified Trilinear Skeleton Curve. A typical skeleton curve of the energy-dissipation joint in the steel-engineered bamboo hybrid frame is presented in Figure 3, which has three segments: a straight line, a hardening segment with a continuously changing stiffness, and a softening stage with a slight decline after the peak load.

There are two critical points after the yielding, i.e., the peak point and the ultimate point. The comparison of the negative and positive values (absolute moments and rotations) of the two critical points is presented in Table 4, which shows that the errors of the two absolute moments and rotations are less than $5 \%$, within the acceptable range. But the size relationship of the two values cannot be determined in designing since the EDP yields in an uncertain side first. To solve the problem and ensure the design redundancy, the minimum moments and rotations of the two absolute values were selected to represent the peak/ultimate moment and rotation in positive and negative directions.

In this paper, a symmetric trilinear simplified skeleton curve is selected to relatively match with the experimental skeleton curve. In Figure 4, points $Y, P$, and $U$ refer to the yield point, peak point, and ultimate point of the joint, respectively. Therefore, six key values of the simplified trilinear skeleton curve should be determined based on the experimental skeleton curves. $M_{y}$ and $\theta_{y}$ represent the moment and rotation of Point $Y$, respectively; $M_{p}$ and $\theta_{p}$ are the moment and rotation of Point P, respectively; $M_{u}$ and $\theta_{u}$ are the moment and rotation of Point $U$, respectively. $K_{1}$, $K_{2}$, and $K_{3}$ are the moment stiffness values of each segment belonging to the simplified skeleton curve of the energydissipation joint.

4.1.1. Rotations of the Skeleton Curve. The yield point, which is also called the soft point, refers to the critical state where the load and displacement curves at the end of the beam begin to deviate from the linear variation [34]. Combined with the test phenomenon, the yield point should be considered as the mutation point where the slope of the skeleton curve begins to change and the point where the EDP begins to buckle.

The initial yielding is the point when the stress of EDP reaches the yield strength of steel, $f_{y}$. Thus, the tensile or compressive force in EDP must be $F_{\mathrm{EDP}}=f_{y} b t$ when initial yielding takes place; from the deformation of energy-dissipation joint in the elastic stage presented in Figure 5, the initial yield moment can be calculated by

$$
M_{E}=F_{\mathrm{EDP}}(h+t)=f_{y} b t(h+t) .
$$

The initial moment stiffness of the connection can be calculated by $K_{E}=f_{y} b t(h+t) / \theta_{E}$, where $\theta_{E}$ represents the rotation of connection, which can be calculated by equation (2) as follows:

$$
\begin{aligned}
\theta_{E} & =\frac{f_{y}}{E(h+t) / 2 l}=\frac{2 f_{y} l}{E(h+t)}, \\
K_{E} & =\frac{E b t(h+t)^{2}}{2 l},
\end{aligned}
$$

where $E$ represents Young's module of the steel; $b$ and $t$ are the width and the thickness of EDP, respectively; $l$ represents the length of EDP; and $h$ stands for the clear distance between the two EDPs. 
TABLE 4: The comparison of maximum and minimum moment and rotation.

\begin{tabular}{|c|c|c|c|c|}
\hline Specimen & $J-6$ & $J-8$ & $J-10$ & $J-12$ \\
\hline Positive peak moment and rotation $(\mathrm{kN} \cdot \mathrm{m} / \mathrm{rad})$ & $76.81 / 0.000873$ & $87.06 / 0.001171$ & $88.63 / 0.001226$ & $88.18 / 0.001049$ \\
\hline Negative peak moment and rotation $(\mathrm{kN} \cdot \mathrm{m} / \mathrm{rad})$ & $-78.96 /-0.000862$ & $-88.72 /-0.001150$ & $-90.09 /-0.001215$ & $-85.79 /-0.001059$ \\
\hline Absolute error $(\%)$ & $-2.72 /+1.26$ & $-1.87 /+1.79$ & $-1.62 /+0.90$ & $+2.71 /-0.95$ \\
\hline Positive ultimate moment and rotation $(\mathrm{kN} \cdot \mathrm{m} / \mathrm{rad})$ & $62.05 / 0.001390$ & $69.91 / 0.00180$ & & \\
\hline Negative ultimate moment and rotation $(\mathrm{kN} \cdot \mathrm{m} / \mathrm{rad})$ & $-63.17 /-0.001431$ & $-72.02 /-0.001855$ & & \\
\hline Absolute error $(\%)$ & $-1.77 /-2.87$ & $-2.93 /-2.96$ & & \\
\hline
\end{tabular}

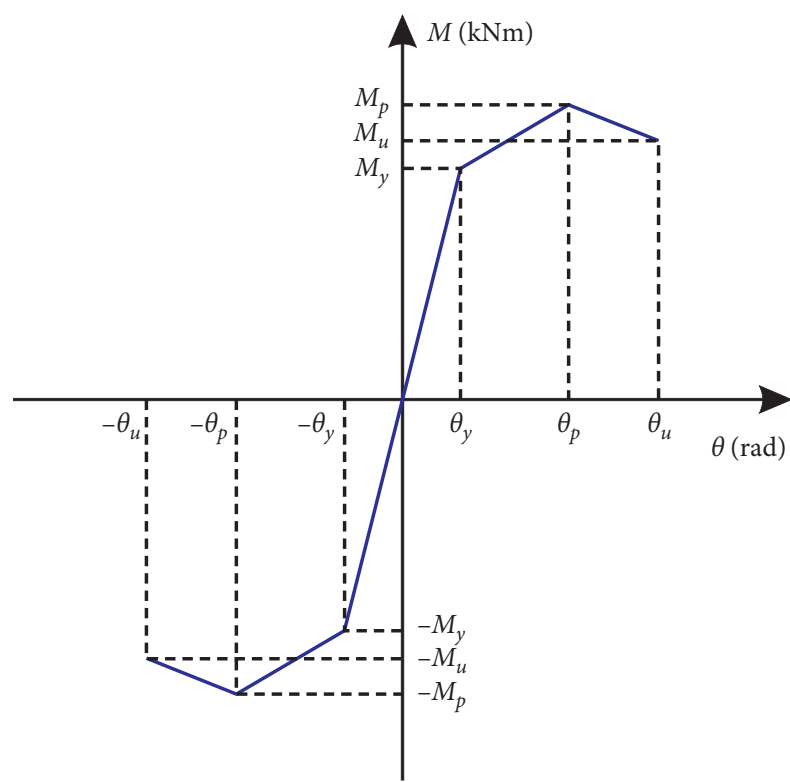

FIGURE 4: The simplified trilinear skeleton curve proposed in this work.

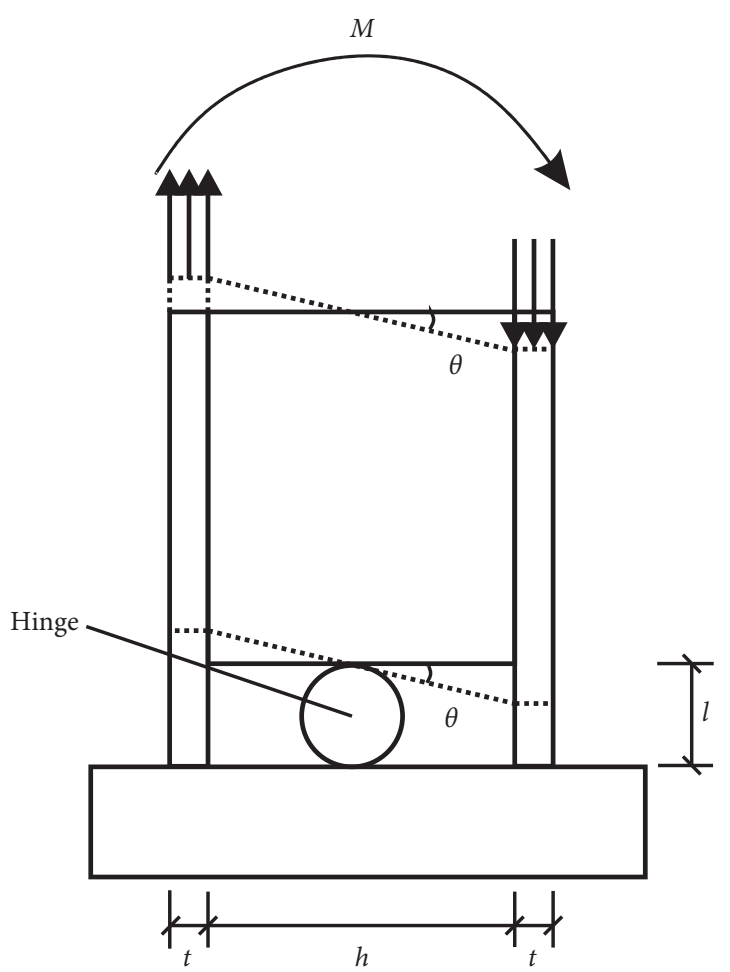

FIGURE 5: The elastic deformation of the energy-dissipation joint.
The comparison of the experimental and the theoretical elastic stiffness is presented in Table 5, which shows that the errors between them are all within $5 \%$. Therefore, $K_{E}$ can be considered as the stiffness of stage I.

With all the rotations obtained from the tests, linear regression algorithm in ORIGIN was selected to describe the relation between each rotation, i.e., yield rotation $\theta_{y}$, peak rotation $\theta_{P}$, and ultimate rotation $\theta_{u}$ with the initial rotation $\theta_{E}$, respectively. The result shows that the relationship between them are all constants. Thus, three coefficients (i.e., $\alpha_{1}$, $\alpha_{2}$, and $\alpha_{3}$ ) are introduced to obtain them starting from the initial rotation $\theta_{E}$ as follows: $\theta_{y}=\alpha_{1} \theta_{E}, \theta_{p}=\alpha_{2} \theta_{E}$, and $\theta_{u}=\alpha_{3} \theta_{E}$. Table 6 shows the coefficients of rotation in the simplified trilinear skeleton curve.

4.1.2. Load-Carrying Capacity and Ultimate States of the Joint. The load-carrying capacity is studied considering the following hypotheses: (1) the shear of the EDPs and the moment of the hinge can be omitted to ensure that the steel hinge and pair of EDPs can completely carry the shear force and moment, respectively; (2) all of the connections between the engineered bamboo beam and the stub, steel column, and base panel are considered as rigid connections; and (3) the friction of the hinge is ignored.

Since the buckling of the EDPs dominates the momentcarrying capacity of the joint, it is necessary to explore the mechanical behavior of EDPs. After getting the maximum reaction force of buckling, the peak moment of the energydissipation joint can be obtained by $F_{\mathrm{EDP}}(h+t)$. Finite element method (FEM) in ABAQUS was utilized to obtain numerical simulation of the energy-dissipation plate under axial loading. The plate was divided in two segments, namely, (1) the real energy-dissipation segment (red part) and (2) the weld segment (blue part) in Figure 6, to better understand the mechanism. The boundary conditions were set the same as for the energy-dissipation joint: only the outof-plane ends movement was constrained. The connection between the two segments in ABAQUS was set as "tie" (a kind of constrains), which indicated the rigid connection of them. The displacement/force was exerted on the reference point, which was coupled with the top surface of the EDP. The established 3D FE model is shown in Figure 6.

The element type of C3D8R (8-node linear brick element, reduced integration with hourglass control) in ABAQUS was chosen to simulate the large deformation of the actual dissipation segment for its better precision and computing efficiency, while the other components type C3D20R (20-node linear brick element, reduced integration 
TABLE 5: Comparison of the experimental and the theoretical elastic stiffness.

\begin{tabular}{lcccc}
\hline Specimen & $J-6$ & $J-8$ & $J-10$ & $J-12$ \\
\hline $\begin{array}{l}\text { Experimental elastic stiffness } \\
(\mathrm{kN} \cdot \mathrm{m})\end{array}$ & 139819 & 137719 & 135781 & 137168 \\
$\begin{array}{l}\text { Theoretical elastic stiffness } \\
(\mathrm{kN} \cdot \mathrm{m})\end{array}$ & 136282 & 137595 & 138915 & 140241 \\
Error $(\%)$ & -2.60 & -0.09 & +2.26 & +2.19 \\
\hline
\end{tabular}

TABLE 6: Coefficients of rotation in the simplified trilinear skeleton curve.

\begin{tabular}{lccc}
\hline Specimen & $\alpha_{1}$ & $\alpha_{2}$ & $\alpha_{3}$ \\
\hline$J-6-1$ & 0.85 & 2.01 & 2.85 \\
$J-8-1$ & 0.87 & 2.07 & 3.24 \\
$J-8-2$ & 0.84 & 2.05 & 2.96 \\
$J-8-3$ & 0.85 & 2.13 & 3.20 \\
Calculated value & 0.85 & 2.07 & 3.06 \\
Standard deviation & 0.04 & 0.04 & 0.16 \\
\hline
\end{tabular}
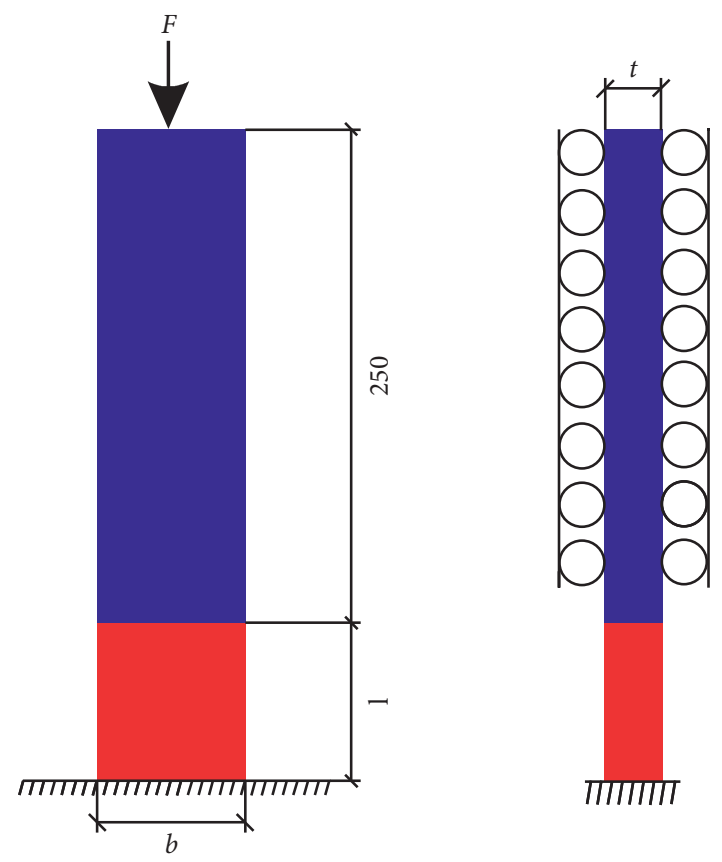

FIGURE 6: FE model and boundary condition.

with hourglass control) were adopted since there is no need for large strain and complex damage evolution. In the tests, the behavior of EDPs turns out to be in the elastoplastic range, so the whole life stage, i.e., elastic stage, hardening stage, and softening stage, should be included in the strainstress relation. Figure 7 shows the stress and strain relation of steel. Formulas (4) to (8) show the transformation from nominal to real strain-stress relationship. Besides that, nonnegligible damage of the EDPs was observed in the process of cyclic loading, so the ductile damage criteria was chosen to simulate the evolution of the material damage, as presented in Figure 8.

The transformation of the real and nominal strain-stress relationship of the steel can be explained as follows:

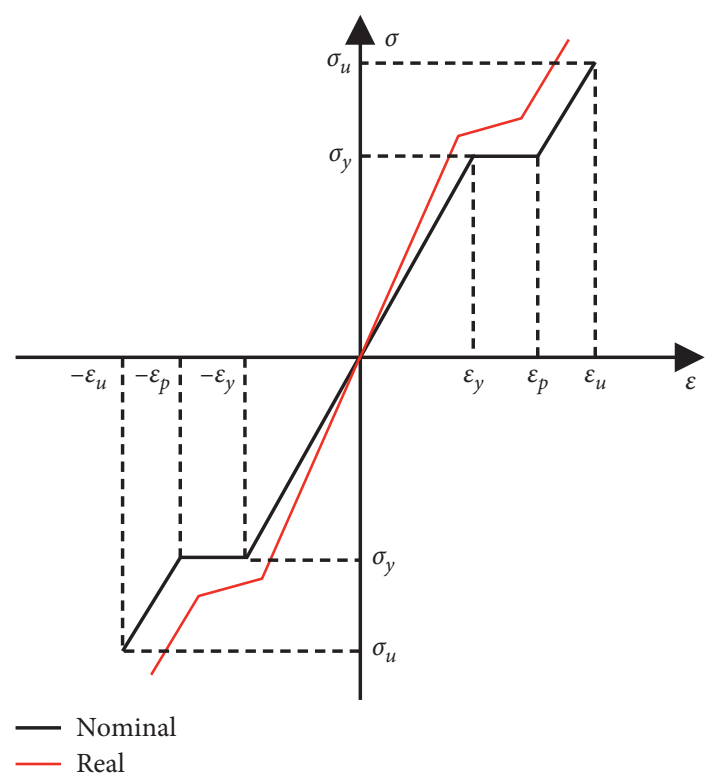

FIgURE 7: Strain-stress relationship of the EDP.

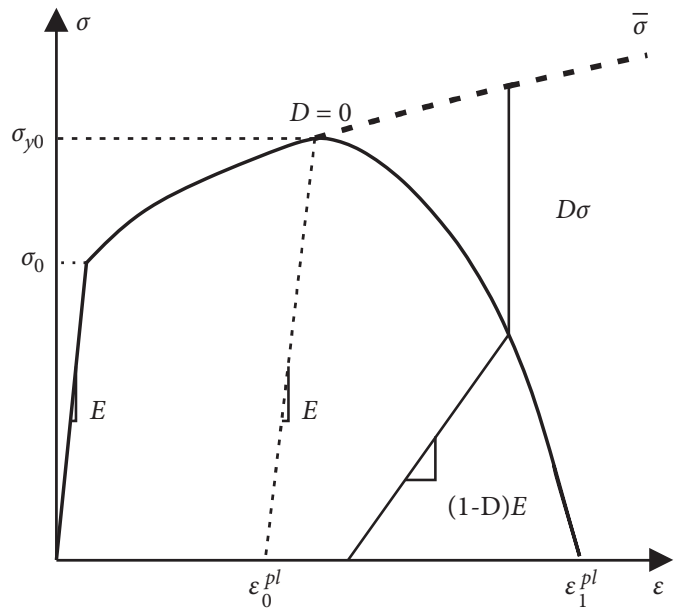

FIGURE 8: The strain-stress relationship of the damage degradation model.

considering the incompressibility of the plastic deformation, the volume of the material does not change after large deformations, and the following equations can be obtained:

$$
\begin{aligned}
l_{0} A_{0} & =l A, \\
A & =A_{0} \frac{l_{0}}{l},
\end{aligned}
$$

where $l$ and $l_{0}$ and $A$ and $A_{0}$ refer to the initial and final (i.e., after large deformations) lengths and cross sections of the test material.

The nominal stress $\sigma_{\text {nom }}$ can be calculated as the force $F$ divided by the initial cross section. Substituting $A$ in the computation of strain, the real stress $\sigma_{\text {rea }}$ can be presented as

$$
\sigma_{\text {rea }}=\frac{F}{A}=\frac{F}{A_{0}} \frac{l}{l_{0}}=\sigma_{\text {nom }}\left(\frac{l}{l_{0}}\right) \text {, }
$$


where $l / l_{0}$ is equal to $1+\varepsilon_{\text {nom }}$; in this way, the relationship of nominal and real strain and stress can be described as

$$
\begin{aligned}
& \sigma_{\text {rea }}=\sigma_{\text {nom }}\left(1+\varepsilon_{\text {nom }}\right), \\
& \varepsilon_{\text {rea }}=\int_{l_{0}}^{l} \frac{d l}{l}=\ln \frac{l}{l_{0}}=\ln \left(1+\varepsilon_{\text {nom }}\right),
\end{aligned}
$$

where $\varepsilon_{\text {nom }}$ and $\varepsilon_{\text {rea }}$ represent nominal and real strains, respectively.

The transformation of the detailed nominal and real strain and stress of the steel is presented in Table 7.

The stress and deformation of the EDP at the maximum displacement are shown in Figures 9(a) and 9(b). Von Mises stress nephogram is applied to show the stress distribution. The maximum stress or strain occurs mainly in the actual dissipation segment, while the other parts remain in the elastic range. It corresponds well with the design aims and failure mode of the tests.

Figure 9(c) shows the displacement-force relationship of the EDP, whereas the loading capacity of the energydissipation joint can be obtained from equation $M_{E}=$ $F_{\text {EDP }}(h+t)$ [28]. The result indicates that the relative errors between the tests and simulations of the four energy-dissipation joint are all less than 15\%, within the acceptable range.

Considering the fact that the cross section of EDP cannot fully yield when connection failed, a coefficient $\eta=M_{p} /$ $\left[f_{\mathrm{u}} b t(h+t)\right]$ is used to quantify the partial yielding effect, where $f_{\mathrm{u}}$ is the ultimate strength of the steel.

The size of the energy-dissipation plate has the prevalent influence on the moment-carrying capacity and ductility of the energy-dissipation joint. FE simulations were conducted by varying only width (from $50 \mathrm{~mm}$ to $100 \mathrm{~mm}$ ), thickness (from $6 \mathrm{~mm}$ to $12 \mathrm{~mm}$ ), cross section (from $500 \mathrm{~mm}^{2}$ to $1000 \mathrm{~mm}^{2}$ ), and length-to-thickness ratio (from 6.6 to 16). The correlations between loading capacity and these parameters were analyzed in SPSS, and the results are presented in Table 8. The results revealed that the Pearson correlations of the four elements are all greater than 0.6 , indicating the pronounced relation of these elements with the loading capacity of energy-dissipation plate. Table 8 also shows the reliability of these parameters which equals to $1-\xi$, and $\xi$ refers to the maximum variation range when the other parameters changes with one parameter determined. The conclusion that length-to-thickness ratio can serve as a stable and reliable parameter compared with thickness and width can be drawn. In this paper, the length-to-thickness ratio was chosen as an independent variable and $\eta\left(M_{p} /\right.$ $\left.\left[f_{\mathrm{u}} b t(h+t)\right]\right)$ as the dependent variable to explore the loading capacity of the energy-dissipation joint.

Other 88 FE simulations by varying length-tothickness ratio of the $\operatorname{EDP}(\lambda=l / t)$ were carried out based on the same method above. It turned out that the coefficients $\eta$ and $\lambda$ tend to have a negative exponential curve. An empirical relationship between $\eta$ and $\lambda$ can be obtained by data fitting which is expressed as follows [28]:

$$
\begin{aligned}
\eta & = \begin{cases}0.978, & 6.6 \leq \lambda \leq 7.2, \\
0.749+1.150 e^{-(\lambda / 1.897)}, & 7.2<\lambda \leq 16.0,\end{cases} \\
M_{p} & =\eta f_{\mathrm{u}} b t(h+t) .
\end{aligned}
$$

The comparison of the peak moments computed by equation (10) with those obtained by testing for groups J-6 and $J-8$ shows good agreements, with all the relative errors less than 15\% [28]. By combining the above hypotheses with finite element simulation performed in ABAQUS, the loadcarrying capacity of the energy-dissipation joint can be estimated by equation (10). In accordance with the Chinese standard GB50017-2017 [32], 0.85M $M_{p}$ is taken as the ultimate moment in the simplified skeleton curve, shown as follows:

$$
M_{u}=0.85 M_{p}
$$

4.2. Method to Obtain the Simplified Skeleton Curve. The calculation flow chart for constructing the simplified trilinear skeleton curve is presented in Figure 10. The elastic stiffness and rotation can be calculated at the first step by assigning the sizes of the joint and its mechanical properties related to Young's modulus and the yield strength. The yield, peak, and ultimate rotations of the joint can be obtained by three coefficients multiplying the elastic rotation, respectively. Hence, the coordinates of the yield point can be gotten. The other two moments of the critical points of the simplified skeleton curve can be calculated from equations (10) and (11). With all the values of the critical points, the stiffness of the three working stages can be calculated as follows:

$$
\begin{aligned}
& K_{1}=K_{E}, \\
& K_{2}=\frac{M_{p}-M_{y}}{\theta_{m}-\theta_{y}}=\frac{M_{p}-\alpha_{1} M_{E}}{\left(\alpha_{2}-\alpha_{1}\right) \theta_{E}}, \\
& K_{3}=\frac{M_{u}-M_{p}}{\theta_{m}-\theta_{y}}=\frac{M_{u}-M_{p}}{\left(\alpha_{3}-\alpha_{2}\right) \theta_{E}} .
\end{aligned}
$$

\section{Simplified Hysteretic Rules}

To examine the theoretic hysteretic rules of the energydissipation joint, a single loop within the whole hysteresis loops of $J-8-1$ is highlighted, as shown in Figure 11. The shape and feature of the experimental hysteresis loops were analyzed, and some conclusions were reached: (1) the reverse $S$-shape or $Z$-shape of the hysteresis loops indicates their pronounced pinching characteristics, (2) the relation of $M-$ $\theta$ in the loading process is a straight line, and (3) the reloading and unloading relations of $M-\theta$ are approximately straight lines, the slope of which is smaller than that of the loading process. Therefore, there is a strength degradation in the reloading and unloading processes.

In Figure 12, a concave hexagon made up of six lines is proposed to simulate the reloading, pinching, and unloading processes of the hysteresis loop, where different slopes 
TABLE 7: Transformation of nominal and real stain and stress of the steel.

\begin{tabular}{lcccc}
\hline Nominal stress $(\mathrm{MPa})$ & Nominal strain & Real stress $(\mathrm{MPa})$ & Real strain & 0.0015 \\
\hline 314 & 0.0015 & 314.5 & 0.003 & 0 \\
315 & 0.003 & 315.9 & 0.139 & 0.0015 \\
445 & 0.15 & 511.75 & 0.34 & 0.137 \\
445 & 0.4 & 580 & - & 0.337 \\
- & - & 600 & 2 \\
\hline
\end{tabular}

Note: the last row of real strain and stress is only used to ensure that the final plastic stress is great enough and the stress-strain relationship keeps increasing in ABAQUS. There is no actual meaning of it.
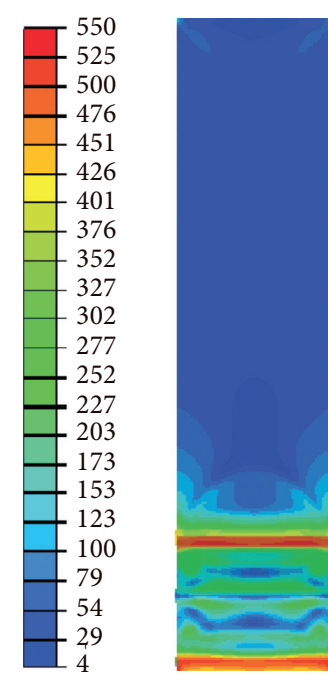

(a)

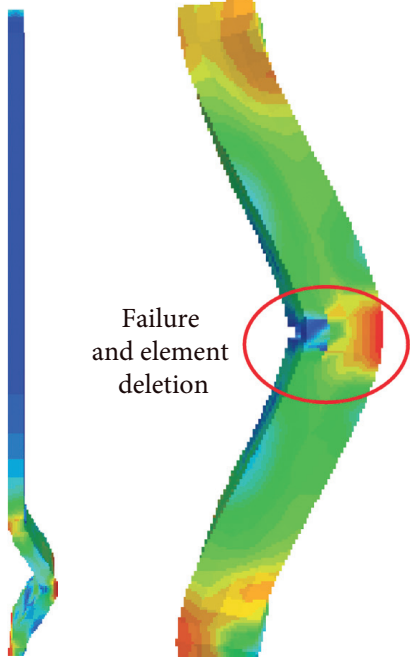

(b)

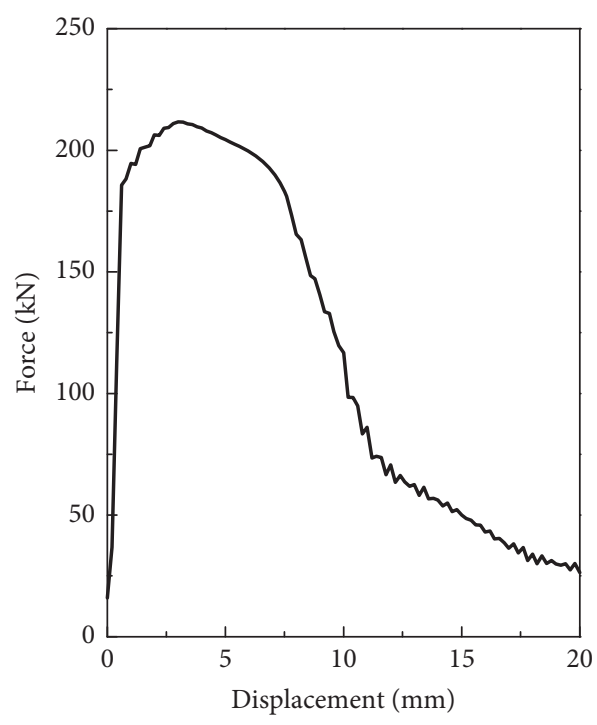

(c)

FIgURE 9: FE simulation results in ABAQUS: (a) stress nephogram of EDP; (b) failure mode; (c) displacement-force curve.

TABle 8: The Pearson correlation and reliability of different parameters.

\begin{tabular}{lcc}
\hline Parameter & Pearson correlation with loading capacity & Reliability $(\%)$ \\
\hline Width of EDP & 0.696 & 62.36 \\
Thickness of EDP & 0.625 & 56.23 \\
Length-to-thickness ratio & -0.792 & 95.47 \\
Cross section of EDP & 0.655 & 50.25 \\
\hline
\end{tabular}

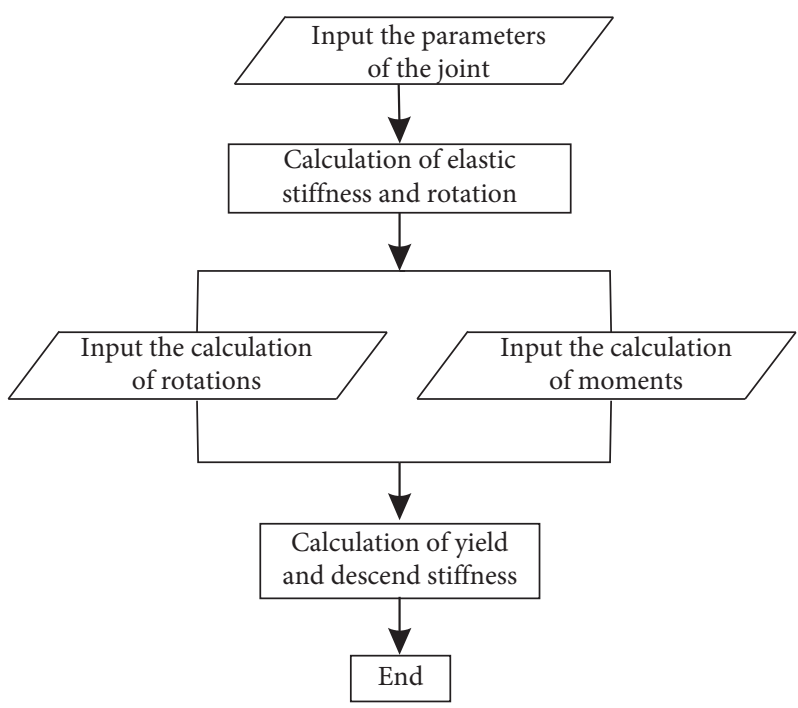

FIgURE 10: Calculation flow chart for constructing the simplified trilinear skeleton curve. 


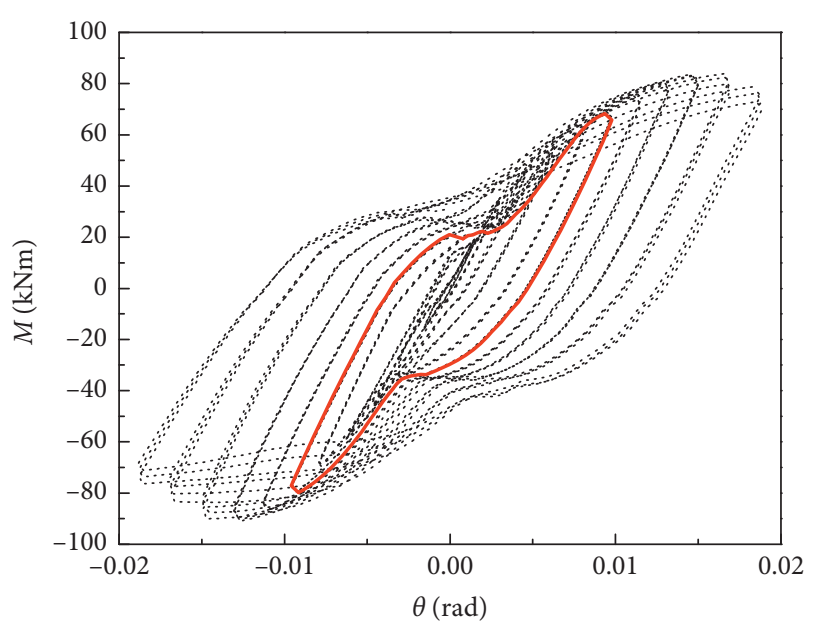

FIgURE 11: Hysteresis loops of the joint.

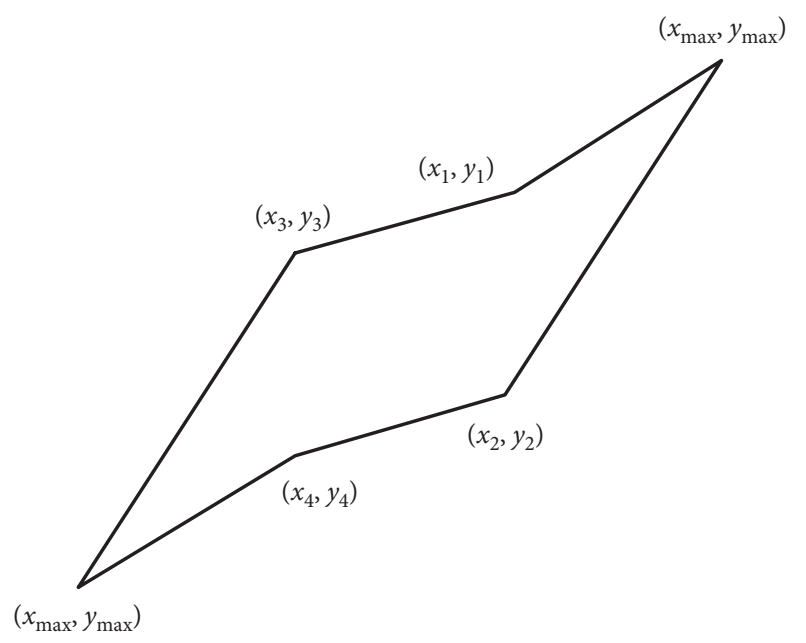

Figure 12: Simplified hysteretic rule of the joint.

between loading and unloading can simulate its stiffness degradation. The advantages of this type of simplified hysteretic rules are presented in the following: (1) the four movable points in the hexagon indicate that the hexagon can be changed into different shapes; i.e., there is flexibility to simulate hysteresis loops of various shapes; (2) with the critical points properly determined, the hysteretic characteristics of the loop, such as the stiffness of reloading and unloading, and the dissipated energy can be simultaneously simulated without losing precision.

In the concave hexagon, the maximum and minimum points, got from the skeleton curve, refer to the maximum/ minimum reaction forces when the corresponding displacements are exerted. The other four points are related to the pinching and reloading stiffness deterioration of the energy-dissipation joint. Point $\left(x_{1}, y_{1}\right)$ and Point $\left(x_{4}, y_{4}\right)$ serve as "breaking points" that indicate the extend of pinching. The combination of Point $\left(x_{1}, y_{1}\right)$ and Point $\left(x_{3}, y_{3}\right)$ or Point $\left(x_{2}, y_{2}\right)$ and Point $\left(x_{4}, y_{4}\right)$ can be used to calculate the reloading stiffness, which is lower than $K_{1}$ because of the deterioration of pinching.
5.1. Parametric Optimization. The genetic algorithm (GA) is a metaheuristic inspired by the natural selection process, which belongs to the larger class of evolutionary algorithms (EA). In recent studies, GAs have proven their pronounced advantages $[35,36]$, i.e., the simplicity, robustness, and insensitivity of initial values for global optimization problems of some large and complex nonlinear systems. They are commonly used to generate high-quality solutions for optimization and search problems by relying on bio-inspired operators, such as mutations, crossover, and selection. The mechanism of GA, presented in Figures 13 and 14, can be explained as follows:

(1) Initial value: random solution values of parameters within specified boundary are chosen in the first step to simulate the first generation of the population.

(2) Crossover: to increase the diversity of solution vectors, the operation of crossover is performed. New solution vector may inherit one part from solution vector $A$ and the other part from solution vector $B$. In other words, the new vector is composed of two parts from two different vectors, respectively.

(3) Mutation: if the solution vector of the last or initial generation does not meet the tolerance of the fitness function, vectors with few different values are generated when passed generation by generation. The mutated vectors of the population might reach a relatively great number after serval generations, which will increase the diversity of the solution vectors further.

(4) Selection: the initial, mutated, and crossbreed solution vectors are all checked if they meet the tolerance of the fitness function, which is also the optimization objective of the algorithm. The solution vectors with less errors will become the dominant individuals, which will be passed to the next generation. In this way, the solution vector will be optimized to a fitter one. The process of selection will be repeated generation by generation until the best solution vector occurs.

In Matlab, the GA toolbox can be used to achieve the operations above. The construction of fitness function and boundary determination of the parameters are the two aspects of upmost importance.

In this section, the GA is used to identify and optimize the critical parameters of the hysteretic curve, and the fitness function of the genetic algorithm is shown in the following equation:

$$
J=\operatorname{ABS}[(S-s) / S],
$$

where $S$ and $s$ are the areas of the test and the simplified hysteresis loop, respectively. The range of eight parameters is set as follows: $x_{l}<x<x_{u}$, where $x_{l}$ and $x_{u}$ represent the upper and lower bounds of the variable.

Theoretically, the critical values of the concave hexagon are in the range of the maximum and minimum, but some restrictions must be added to ensure the best fitness for the single hysteresis loop. The method to determine the lower 


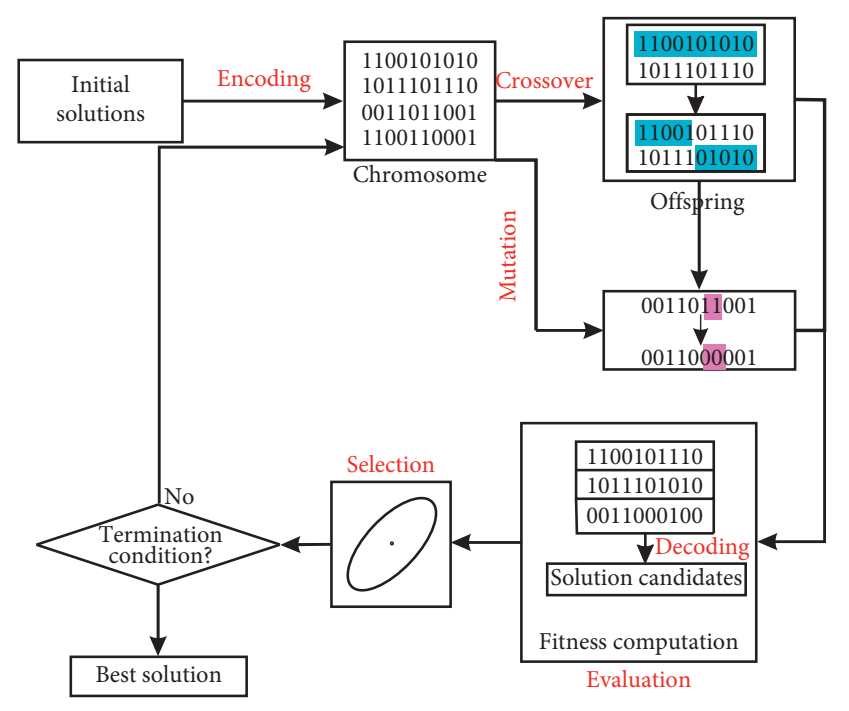

FIGURE 13: Theory and main steps of GA.

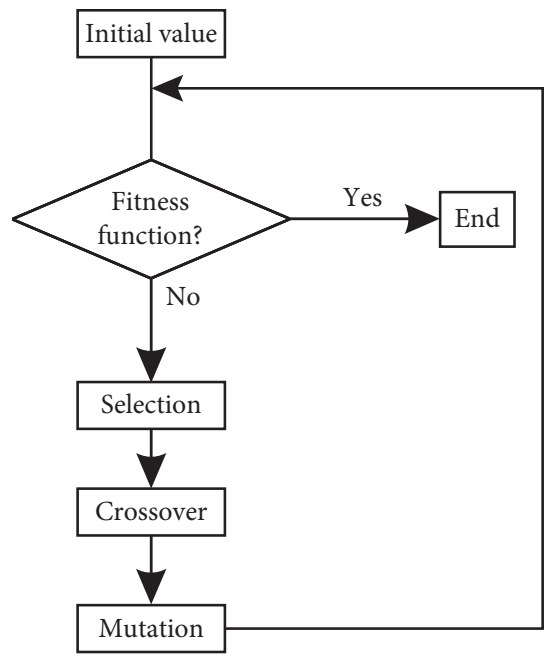

FIGURE 14: Calculation flow chart of GA.

and upper bounds is illustrated in Figure 15 with a single hysteresis loop, where LB represents the lower bound and UB represents the upper bound of the parameter. Two main steps are included in the method: the rough values of each critical points are first found and then expanded to a certain range.

Point 1 and Point 3 are the turning points of the hysteresis loop, whose rough values can be gotten directly from the picture. However, the other two points (Point 2 and Point 4) can be calculated as the cross points of the two tangent lines of the reloading and unloading curves. With the rough values of the four critical points determined, the ranges of each parameters can be set as $[0.90,1.10]$ times the rough values.

Other parameters set in the GA tool are presented as follows: the population size is equal to 1000 , the number of generations is equal to 50 , the ratio of crossover is set as 0.8 , and the function tolerance of function $J$ is set as $10^{-6}$. Parameters of a single loop optimized by the GA are shown in Table 9.

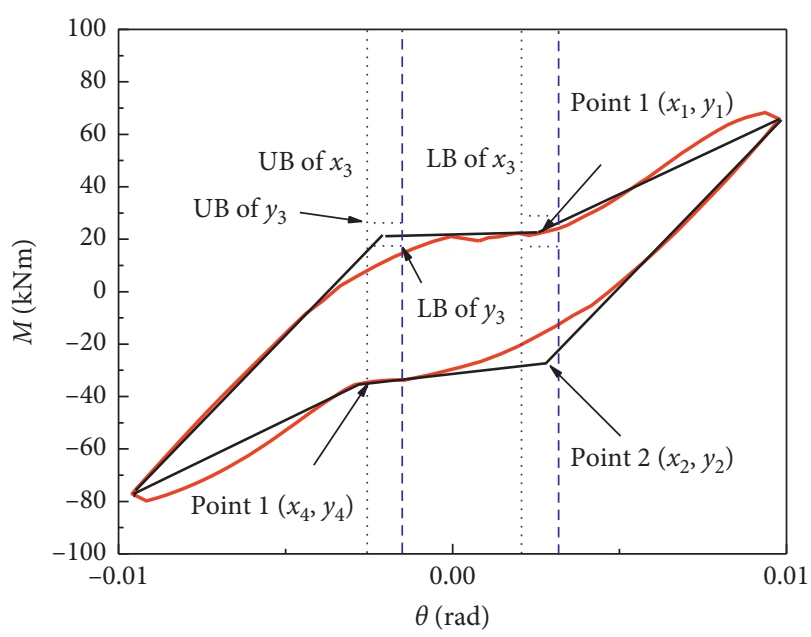

Figure 15: Method to determine the LBs and UBs of the parameters.

Figure 16(a) presents the comparison of the single hysteresis loop between the test and the simplified model; Figure 16(b) shows the relative area error between the test and the simplified model with the increase in the evolution algebra of the populations. From Figure 16(a), the overall trend between the test result and the simplified model indicates their agreement. The latter figure shows that the area error between the test and the simplified model is less than $10^{-6}$, so the energy dissipation of the hexagon is identical to that of the actual test when the simplified hysteretic rule is used.

5.2. Parameters Optimized by the GA. The same method can be used to optimize the parameters of other hysteresis loops, and the data collection processes are identical to that of Section 5.1. The result reveals that the values (displacement and force) of the critical points increase with the increase in maximum displacement or force and the relationships between the two factors tend to be straight lines or nonlinear curves. To make the relationships more explicit, the ratio of $\theta$ to $\theta_{p}$ is selected as the independent variable instead of $\theta$.

As mentioned in Section 3, the maximum and minimum moments and rotations at each cycle can be calculated from the skeleton curve. Thus, eight coefficients (i.e., $\xi_{1}$ to $\xi_{8}$ ) are used to determine the ratio between $x_{1}$, $x_{2}, x_{3}, x_{4}, y_{1}, y_{2}, y_{3}$, and $y_{4}$ to the maximum and minimum values $x_{\max }, x_{\min }, y_{\max }$, and $y_{\min }$ of each hysteresis loop. Detailed definition of $\xi$ is presented in Table 10, and $\mu$ is the ratio of $\theta$ to $\theta_{p}$. Linear algorithm in ORIGIN was selected to describe the relationships of $\mu$ and $\xi$, as shown in Figure 17.

In the analysis of the parameters optimized by the GA, the critical points of the hysteretic rules are related to the ratios of measured rotation $\theta$ to the peak rotation $\theta_{p}$. In the regression analysis, the four critical points considering the effect of $\mu(0.5<\mu<1.5)$ are presented in the following equations: 
TABle 9: Parameters optimized by the GA.

\begin{tabular}{lcccccccc}
\hline Parameters & $x_{1}$ & $y_{1}$ & $x_{2}$ & $y_{2}$ & $x_{3}$ & $y_{3}$ & $x_{4}$ & $y_{4}$ \\
\hline Optimized value & 0.0035 & 23.5089 & 0.0028 & -26.6329 & -0.0032 & 21.513 & -0.0032 & -26.6855 \\
Upper bound & 0.004 & 25 & 0.004 & -23 & -0.002 & 25 & -0.003 & -23 \\
Lower bound & 0.003 & 21 & 0.002 & -29 & -0.004 & 21 & -0.004 & -29 \\
\hline
\end{tabular}

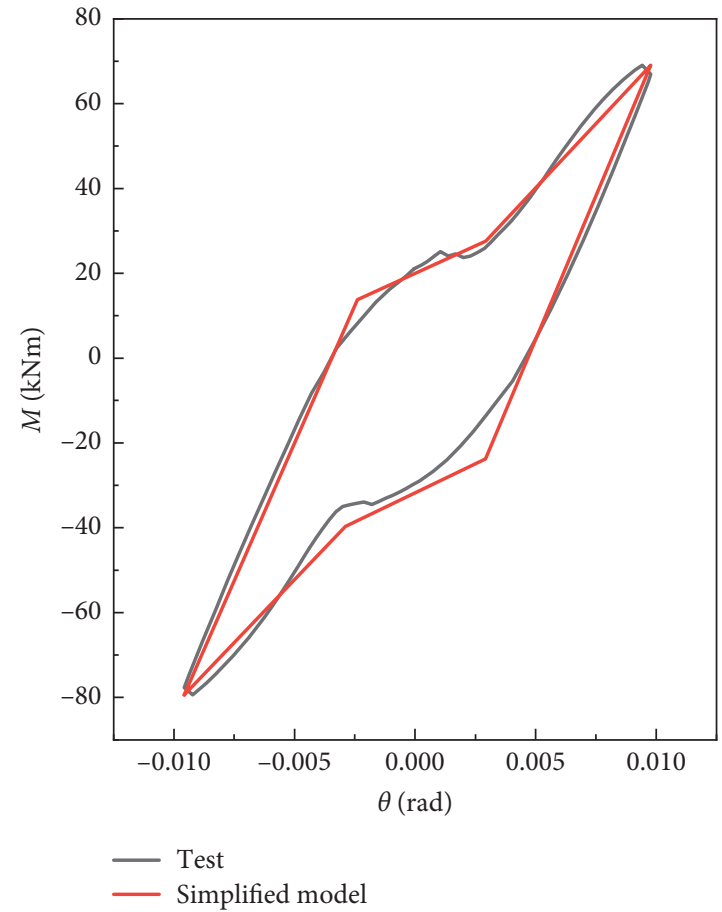

(a)

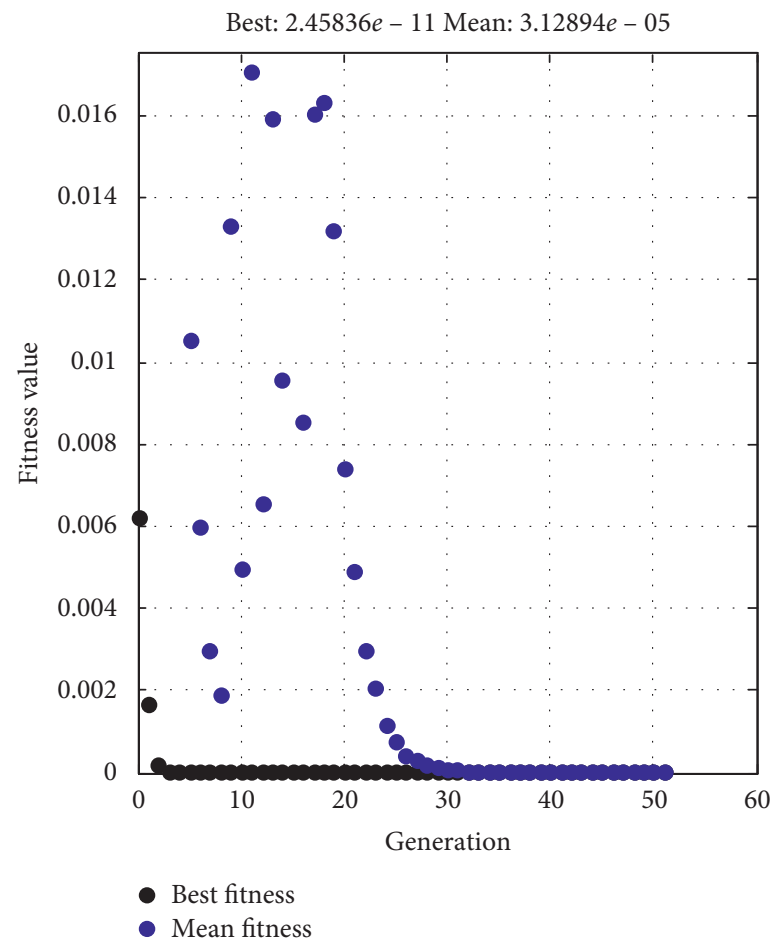

(b)

FIGURE 16: Comparison of the (a) hysteretic curve and (b) generation-absolute error curve between the test and the simplified model.

TABLe 10: Detail information of $\xi$.

\begin{tabular}{cccccccc}
\hline$\xi$ & $\xi_{1}$ & $\xi_{2}$ & $\xi_{3}$ & $\xi_{4}$ & $\xi_{5}$ & $\xi_{6}$ & $\xi_{7}$ \\
\hline$x_{1} / x_{\max }$ & $y_{1} / y_{\max }$ & $x_{2} / x_{\max }$ & $y_{2} / y_{\min }$ & $x_{3} / x_{\min }$ & $y_{3} / y_{\max }$ & $x_{4} / x_{\min }$ & $y_{4} / y_{\min }$ \\
\hline
\end{tabular}

$\xi_{1}=\xi_{7}=0.180$

$\xi_{2}=0.550 \mu-0.049$,

$\xi_{3}=\xi_{5}= \begin{cases}0.41, & 0.5 \leq \mu \leq 1.1, \\ 0.51, & 1.1<\mu \leq 1.5,\end{cases}$

$\xi_{4}=\xi_{6}=0.230$,

$\xi_{8}=0.531 \mu-0.025$.

\section{Comparison of the Tests and Simplified Model}

6.1. Comparison of the Skeleton Curves. Based on the flow chart shown in Figure 10, the simplified skeleton curves of the first four groups in Table 1 are obtained, and Figure 18 presents the comparison of the skeleton curve from the test and simplified skeleton curves. The results show that the two skeleton curves are notably consistent with each other and that the simplified skeleton curve can basically simulate the relation of $M$ and $\theta$. 

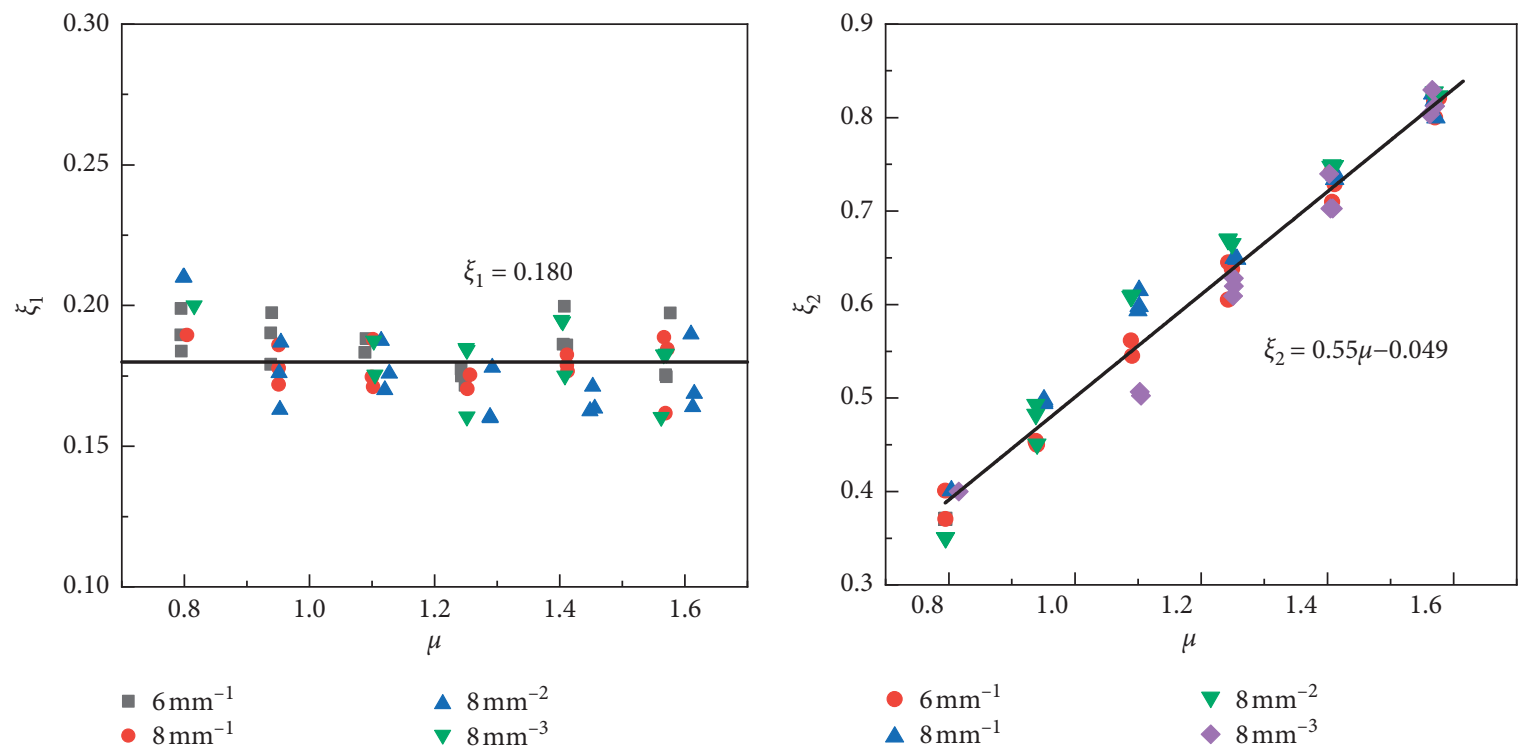

(a)
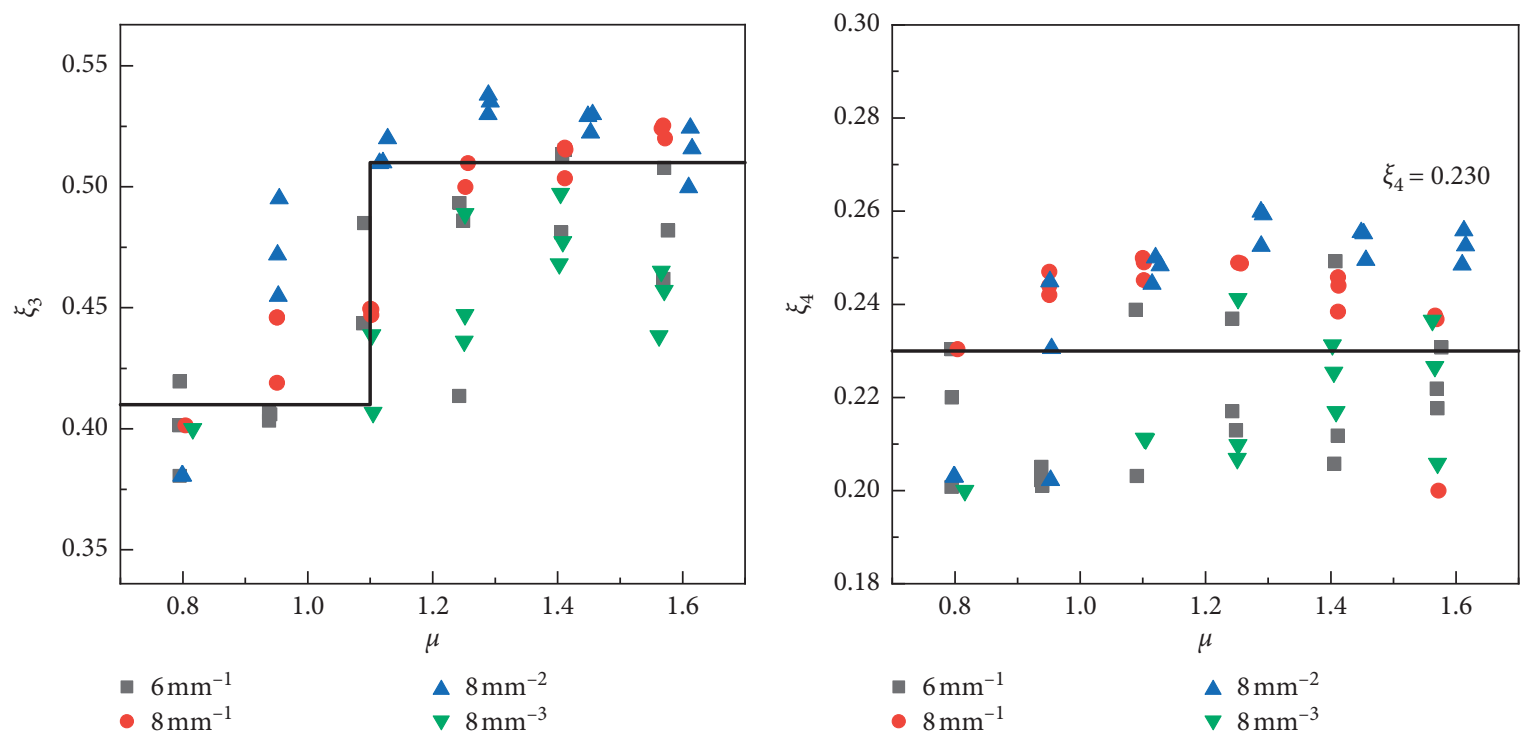

(c)

(d)

Figure 17: Continued. 


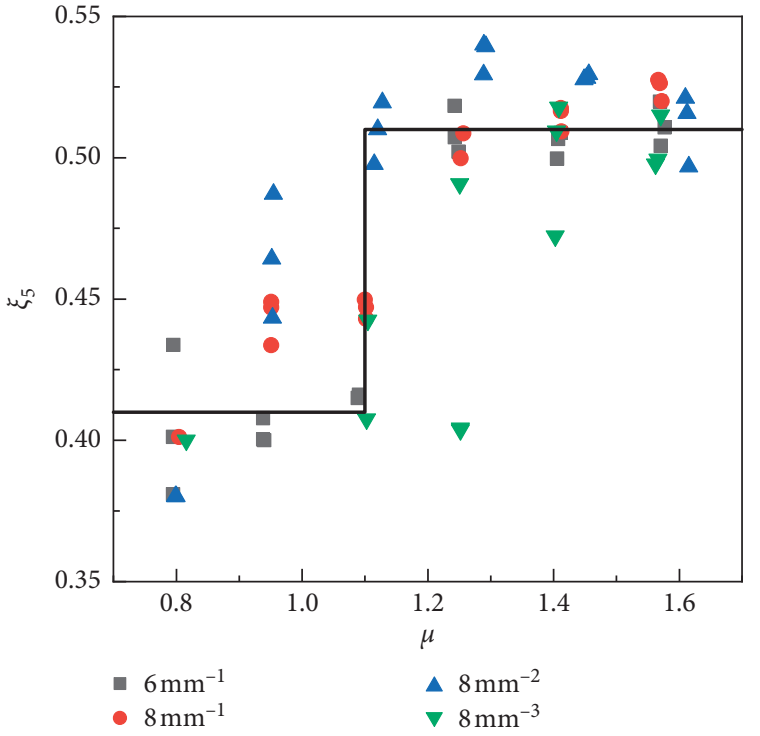

(e)

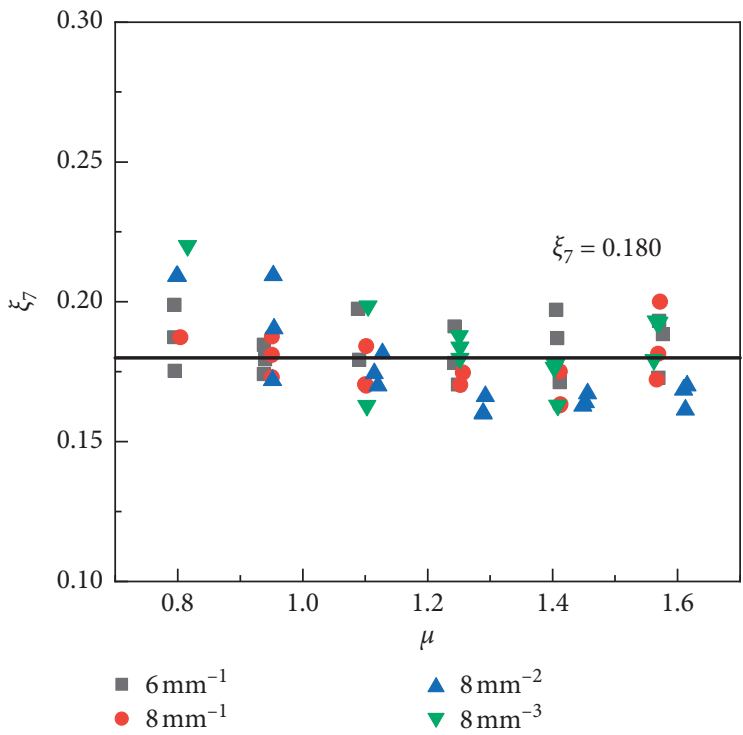

(g)

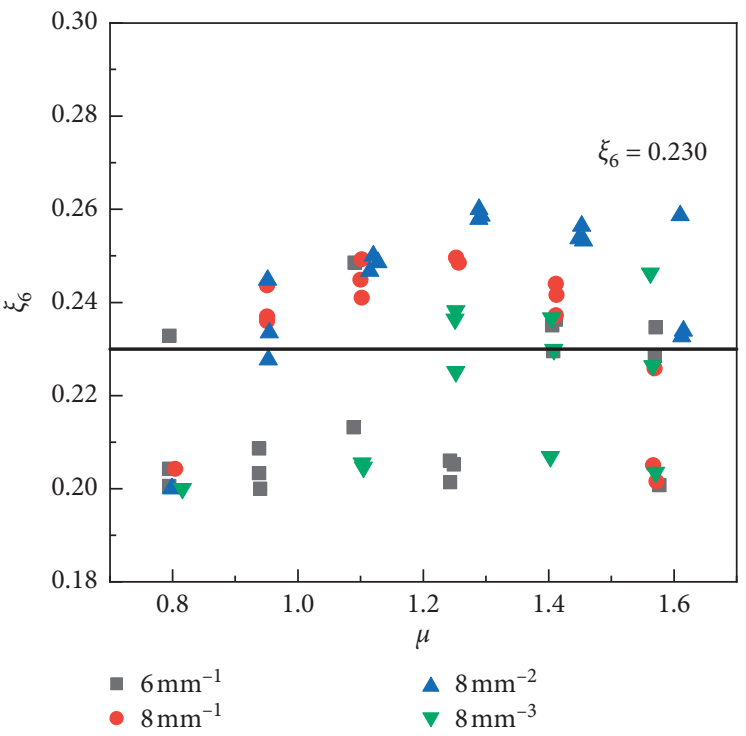

(f)

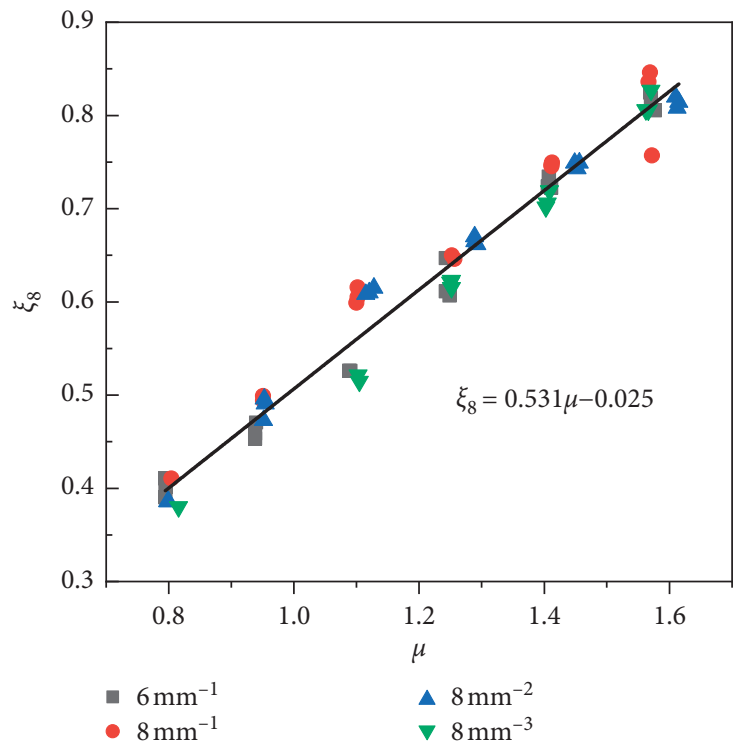

(h)

Figure 17: Parameters optimized by the GA: (a) $\xi_{1}$; (b) $\xi_{2}$; (c) $\xi_{3}$; (d) $\xi_{4}$; (e) $\xi_{5}$; (f) $\xi_{6}$; (g) $\xi_{7}$; (h) $\xi_{8}$.

The comparison between the ductility calculated from the experimental and the predicated skeleton curve is presented in Table 11, which shows that the errors are less than $10 \%$.

6.2. Comparison of Hysteresis Loops. The hysteretic rules for the energy-dissipation joint were simplified as a concave hexagon, the critical points of which were optimized by the GA as previously mentioned. The hysteretic curves obtained from the simplified model and the tests of the first four group in Table 1 are compared in Figure 19.

The comparison between the damping ratio obtained from the experimental and the simplified model is presented in Table 12. The errors are less than $10 \%$, within acceptable range.

6.3. Simplified Restoring Force Model. Combining the simplified skeleton curve and hysteretic rules of the energydissipation joints, a simplified restoring force model of the energy-dissipation joint is constructed, as presented in Figure 20.

In Figure 20, Points 1, 2, and 3 are the yield point, peak point, and ultimate point in the positive direction, respectively, and Point 4, Point 5, and Point 6 are the yield point, peak point, and ultimate point in the negative direction. The 


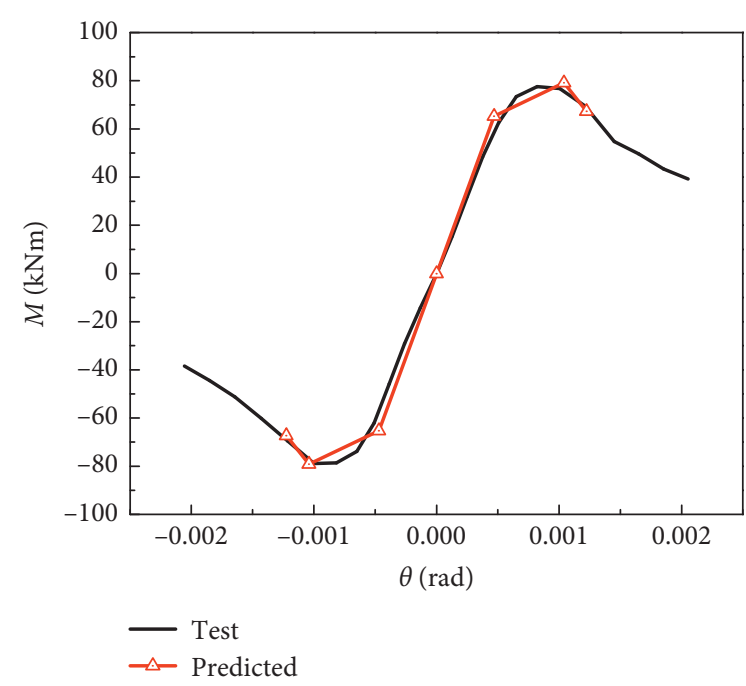

(a)

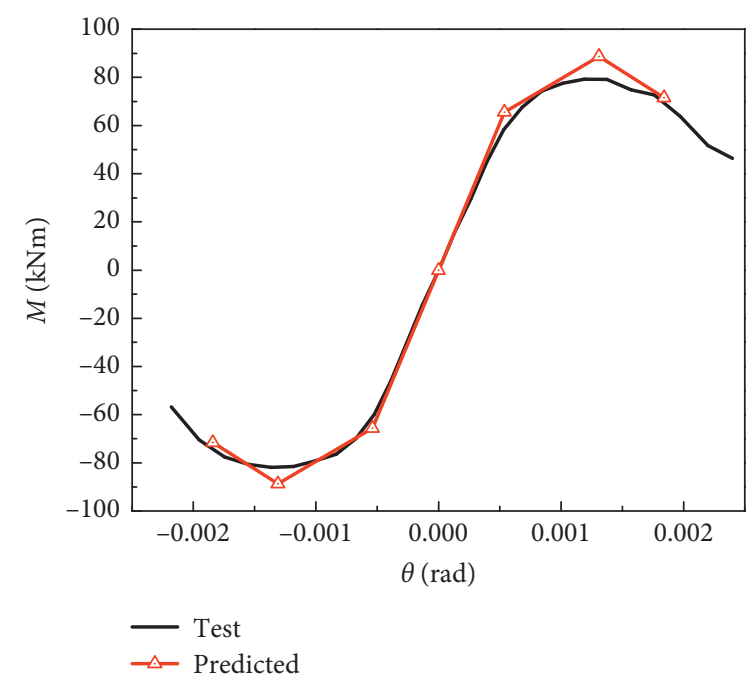

(c)

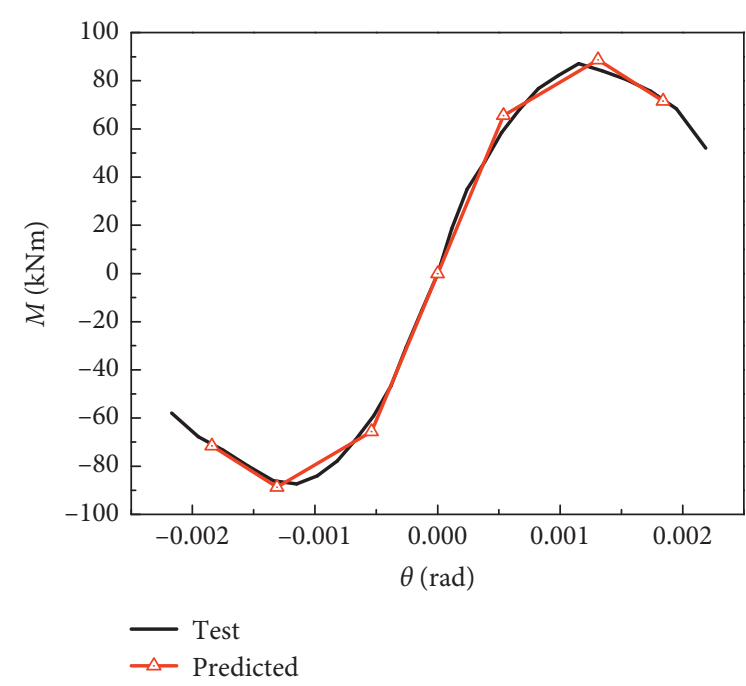

(b)

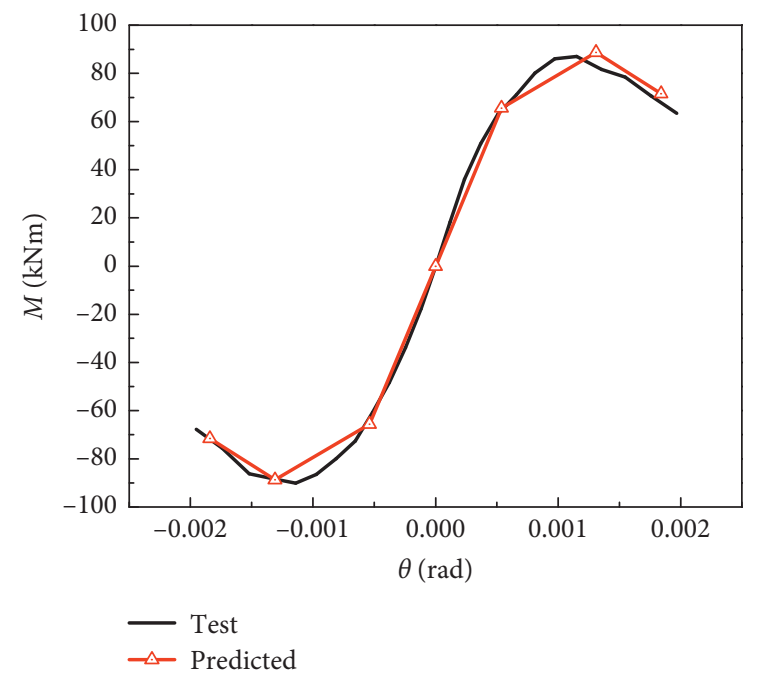

(d)

FIgURE 18: Comparison between the experimental and the predicated skeleton curves for (a) J-6-1, (b) J-8-1, (c) J-8-2, and (d) $J-8-3$.

TABLE 11: Comparison of the ductility from the experimental and the simplified skeleton curves.

\begin{tabular}{|c|c|c|c|c|}
\hline Specimen & $J-6-1$ & $J-8-1$ & $J-8-2$ & $J-8-3$ \\
\hline Ductility of the test & 2.95 & 3.20 & 3.01 & 3.04 \\
\hline Ductility of the simplified skeleton curve & 2.76 & 3.02 & 3.02 & 3.02 \\
\hline Error $(\%)$ & 6.44 & 5.63 & 0.33 & 0.66 \\
\hline
\end{tabular}

detailed loading and unloading path to establish the restoring force model consists of the following steps:

(I) When the maximum load is less than yield moment $M_{y}$, the energy dissipated by the joint is negligible. Both the loading stiffness and unloading stiffness are equal to the elastic moment stiffness $K_{E}$ or preyield moment stiffness $K_{1}$, and the hysteretic rule is a straight line.

(II) When the maximum load is between the yield moment and peak moment, the pinching in the hysteresis loop of the energy-dissipation joints becomes prominent. The shape becomes a reversed 


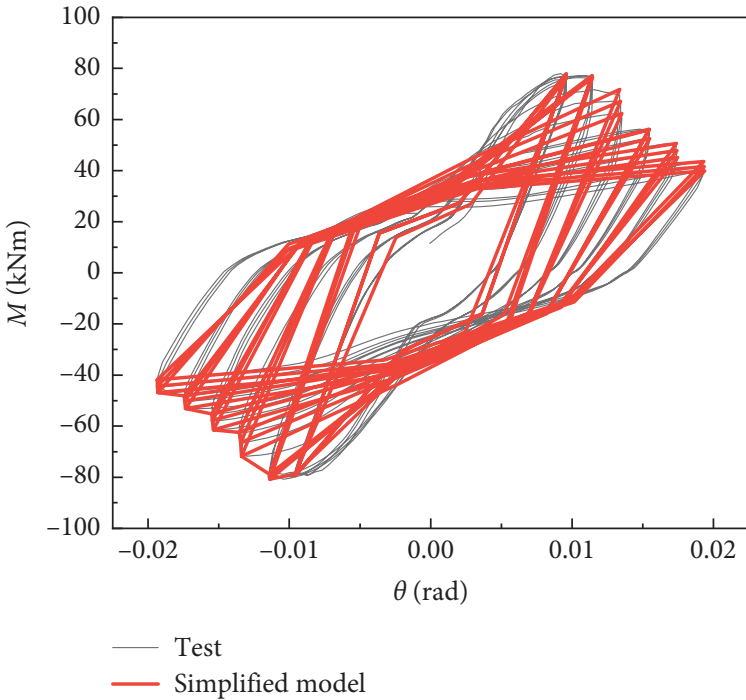

(a)

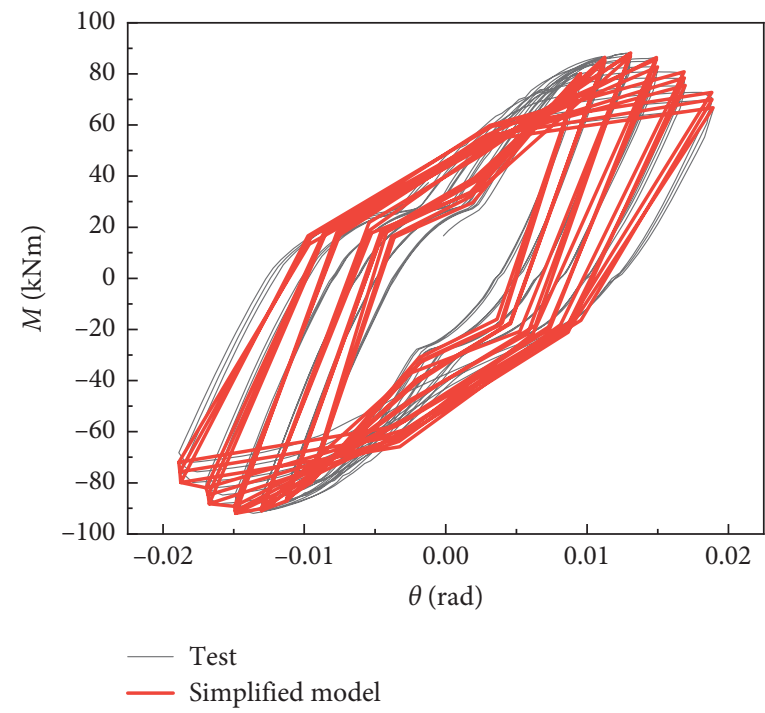

(c)

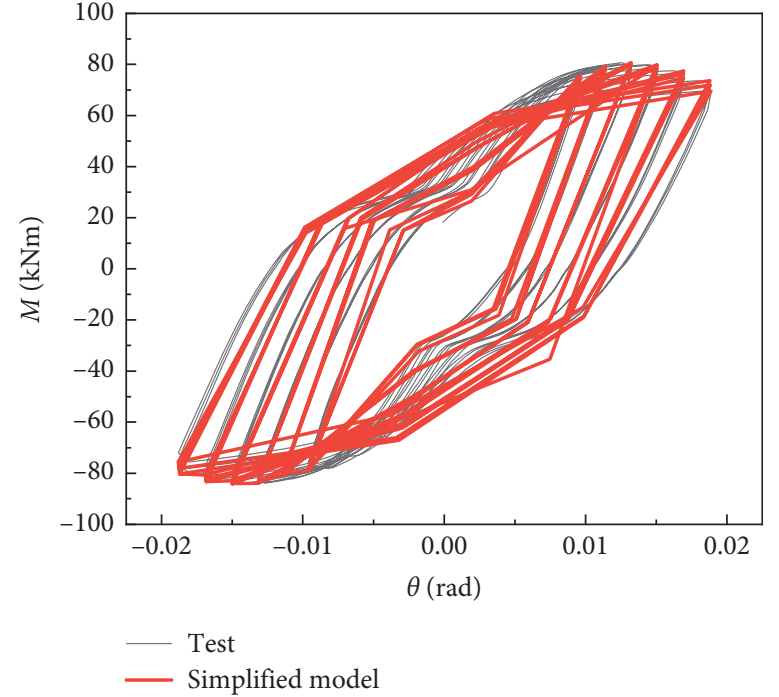

(b)

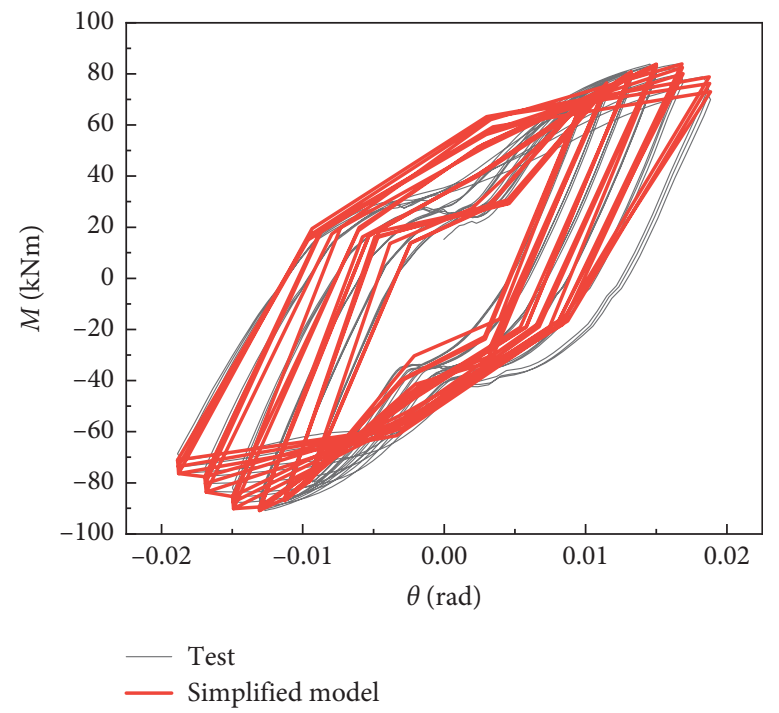

(d)

FIGURE 19: Comparison between the hysteretic curve obtained from the experimental and the simplified model: (a) J-6-1; (b) J-8-1; (c) J-8-2; (d) $J-8-3$.

TABle 12: Comparison of the damping ratio between the test and simplified model.

\begin{tabular}{|c|c|c|c|c|}
\hline Specimen & $J-6-1$ & $J-8-1$ & $J-8-2$ & $J-8-3$ \\
\hline Maximum damping ratio of the test & 0.311 & 0.312 & 0.305 & 0.292 \\
\hline Maximum damping ratio of the simplified model & 0.293 & 0.312 & 0.299 & 0.282 \\
\hline Error $(\%)$ & -5.79 & 0 & -1.97 & -3.42 \\
\hline
\end{tabular}

$S$-shape, and the hysteretic rule in this segment can be simplified as a concave hexagon. The critical point values of this hexagon are presented in equations (11) to (20). The unloading and reloading path is $7 \longrightarrow 13 \longrightarrow 14 \longrightarrow 8 \longrightarrow$ $11 \longrightarrow 12 \longrightarrow 7$.

(III) When the joint reaches the softening stage, the energy dissipated by the joint increases with the displacement due to the lateral loading and the hysteresis loop becomes slightly chubby so that its pinching effect is weaker than that in the stage II. The shape of the hysteresis loop becomes a hexagon. The parameters of the hysteretic rule can be obtained from equations (11) to (20). The unloading and reloading path is $9 \longrightarrow 17 \longrightarrow 18 \longrightarrow 10 \longrightarrow 15 \longrightarrow 16 \longrightarrow 9$. 


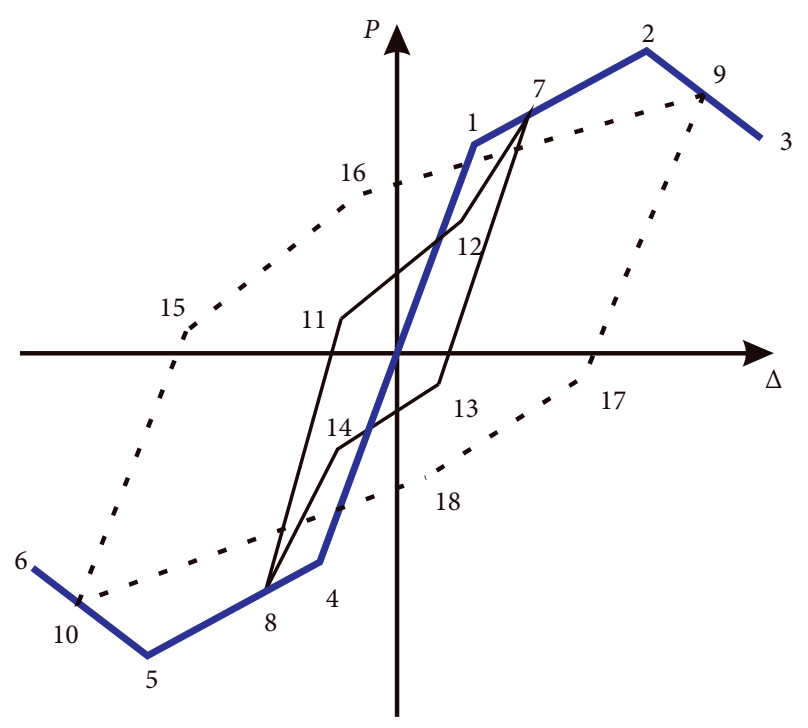

FIGURE 20: Restoring force model of the energy-dissipation joint in a steel-engineered bamboo hybrid frame.

\section{Conclusion}

Based on the experimental skeleton curves of the energydissipation joint in steel-engineered bamboo hybrid frames, a simplified symmetric trilinear skeleton curve and a simplified concave hexagon were established to relatively match with the experimental skeleton curve and hysteretic rules. The errors of ductility and damping ratio between the tests and calculated hysteretic model are all within $10 \%$, and the skeleton curve and hysteresis loops of tests and proposed hysteretic model are in good agreement.

\section{Data Availability}

The XLSX data used to support the findings of this study may be accessed by emailing to the corresponding author. The available time will be six months after the publication since there are still some researches and articles for submission based on this manuscript and the original data.

\section{Conflicts of Interest}

The authors declare that there are no conflicts of interest regarding the publication of this paper.

\section{Acknowledgments}

The study was supported by the National Intensive Research Project (2017YFC0703500) and the National Natural Science Foundation of China (no. 6505000184). Their supports are gratefully acknowledged.

\section{References}

[1] E. Hurmekoski, R. Jonsson, and T. Nord, "Context, drivers, and future potential for wood-frame multi-story construction in Europe," Technological Forecasting and Social Change, vol. 99, pp. 181-196, 2015.
[2] B. Sharma, A. Gatóo, M. Bock, and M. Ramage, "Engineered bamboo for structural applications," Construction and Building Materials, vol. 81, pp. 66-73, 2015.

[3] J. Zhang, M. He, and Z. Li, "Compressive behavior of glulam columns with initial cracks under eccentric loads," International Journal of Advanced Structural Engineering, vol. 10, no. 2, pp. 111-119, 2018.

[4] D. Huang, Y. Bian, A. Zhou, and B. Sheng, "Experimental study on stress-strain relationships and failure mechanisms of parallel strand bamboo made from phyllostachys," Construction and Building Materials, vol. 77, pp. 130-138, 2015.

[5] Z. Chen and Y. H. Chui, "Lateral load-resisting system using mass timber panel for high-rise buildings," Frontiers in Built Environment, vol. 3, p. 40, 2017.

[6] Pei S., Van de Lindt J. W., Pryor S. E., Shimizu H., Isoda H., \& Rammer D, Seismic testing of a full-scale mid-rise building: The NEESWood Capstone Test, MCEER 2010.

[7] Z. Li, M. He, F. Lam, M. Li, R. Ma, and Z. Ma, "Finite element modeling and parametric analysis of timber-steel hybrid structures," The Structural Design of Tall and Special Buildings, vol. 23, no. 14, pp. 1045-1063, 2015.

[8] Z. Li, H. Dong, X. Wang, and M. He, "Experimental and numerical investigations into seismic performance of timbersteel hybrid structure with supplemental dampers," Engineering Structures, vol. 151, pp. 33-43, 2017.

[9] P. Bhat, R. Azim, M. Popovski, and T. Tannert, "Experimental and numerical investigation of novel steel-timber-hybrid system," in Proceedings of the World Conference on Timber Engineering, Quebec City, Canada, August 2014.

[10] C. Loss, M. Piazza, and R. Zandonini, "Connections for steeltimber hybrid prefabricated buildings. part i: experimental tests," Construction and Building Materials, vol. 122, pp. 781-795, 2016.

[11] K. W. Johansen, "Theory of timber connections," Theory of Timber Connections, pp. 249-262, 1949.

[12] A. Bouchaïr, P. Racher, and J. F. Bocquet, "Analysis of dowelled timber to timber moment-resisting joints," Materials and Structures, vol. 40, no. 10, pp. 1127-1141, 2007.

[13] N. Kharouf, G. McClure, and I. Smith, "Elasto-plastic modeling of wood bolted connections," Computers \& Structures, vol. 81, no. 8-11, pp. 747-754, 2003.

[14] Y. Araki, T. Endo, and M. Iwata, "Feasibility of improved slotted bolted connection for timber moment frames," Journal of Wood Science, vol. 57, no. 3, pp. 247-253, 2011.

[15] M. Mohammad and J. H. Quenneville, "Bolted wood-steel and wood-steel-wood connections: verification of a new design approach," Canadian Journal of Civil Engineering, vol. 28, no. 2, pp. 254-263, 2001.

[16] T. Shiratori, A. J. M. Leijten, and K. Komatsu, "The structural behaviour of a pre-stressed column-beam connection as an alternative to the traditional timber joint system," Engineering Structures, vol. 31, no. 11, pp. 2526-2533, 2009.

[17] F. Wanninger and A. Frangi, "Experimental and analytical analysis of a post-tensioned timber connection under gravity loads," Engineering Structures, vol. 70, pp. 117-129, 2014.

[18] Z. Ling, W. Liu, and H. Yang, "Reliability analysis and design recommendations on bond-anchorage of glulam joints with glued-in rod," Journal of Nanjing Tech University (Natural Science Edition), vol. 43, no. 10, 2015, in Chinese.

[19] E. Crayssac, X. Song, Y. Wu, and K. Li, "Lateral performance of mortise-tenon jointed traditional timber frames with wood panel infill," Engineering Structures, vol. 161, pp. 223-230, 2018.

[20] H. Xiong, Y. Liu, Y. Yao, and B. Li, "Experimental study of reinforcement methods and lateral resistance of glued- 
laminated timber post and beam structures," Journal of Tongji University (Natural Science), vol. 5, no. 6, pp. 379-385, 2016, in Chinese.

[21] Z. Li, M. He, and K. Wang, "Hysteretic performance of selfcentering glulam beam-to-column connections," Journal of Structural Engineering, vol. 144, no. 5, Article ID 04018031, 2018.

[22] X. Cai and S. Meng, "Research on restoring force model of the prestressed self-centering concrete frame joints," Engineered Mechanics, vol. 35, no. 1, pp. 182-190, 2018, in Chinese.

[23] A. H. Buchanan and R. H. Fairweather, "Seismic design of glulam structures," Bulletin of the New Zealand Society for Earthquake Engineering, vol. 26, no. 4, pp. 415-436, 1993.

[24] H. J. Larsen and J. L. Jensen, "Influence of semi-rigidity of joints on the behaviour of timber structures," Progress in Structural Engineering and Materials, vol. 2, no. 3, pp. 267277, 2000.

[25] H. Yang, W. Liu, and X. Ren, “A component method for moment-resistant glulam beam-column connections with glued-in steel rods," Engineering Structures, vol. 115, pp. 42$54,2016$.

[26] V. Karagiannis, C. Málaga-Chuquitaype, and A. Y. Elghazouli, "Behaviour of hybrid timber beam-to-tubular steel column moment connections," Engineering Structures, vol. 131, pp. 243-263, 2017.

[27] H. Xiong, Y. Liu, Y. Yao, and B. Li, "Experimental study on lateral resistance of timber post and beam structures strengthened with carbon fiber reinforced polymer," Journal of Tongji University (Natural Science), vol. 10, no. 3, 2015.

[28] Z. Huang, Z. Chen, D. Huang, and Y.-H. Chui, "Cyclic loading behavior of an innovative semi-rigid connection for engineered bamboo-steel hybrid frames," Journal of Building Engineering, vol. 24, Article ID 100754, 2019.

[29] X. Lu, X. Yin, and H. Jiang, "Restoring force model for steel reinforced concrete columns with high steel ratio," Structural Concrete, vol. 14, no. 4, pp. 415-422, 2013.

[30] J. Zhao and H. Dun, "A restoring force model for steel fiber reinforced concrete shear walls," Engineering Structures, vol. 75, pp. 469-476, 2014.

[31] Y. Liu, C. Málaga-Chuquitaype, and A. Y. Elghazouli, "Response and component characterisation of semi-rigid connections to tubular columns under axial loads," Engineering Structures, vol. 41, pp. 510-532, 2012.

[32] National Standard of the People's Republic of China, Standard for Design of Steel Structures, GB50017, China Planning Press, Beijing, China, 2017.

[33] ASTM, Standard Test Method for Cyclic (Revised) Load for Shear Resistance of Vertical Elements of Lateral Force Resisting System for Building. ASTM E2126-11, American Society for Testing Materials, West Conshohocken, PA, 2011.

[34] P. Zhang, Nonlinear Analysis of Reinforced Concrete Seismic Structure, Science Press, Beijing, China, 2003.

[35] Z. Michalewicz, Genetic Algorithms + Data Structures = Evolution Programs, Springer, Berlin, Germany, 1996.

[36] G. Zames, N. M. Ajlouni, N. M. Ajlouni et al., "Genetic algorithms in search, optimization and machine learning," Information Technology Journal, vol. 3, no. 1, pp. 301-302, 1981. 